\title{
Spatial versus Social Mismatch: The Strength of Weak Ties*
}

\author{
Yves Zenou ${ }^{\dagger}$
}

February 4, 2011

\begin{abstract}
The aim of this paper is to provide a new mechanism based on social interactions explaining why distance to jobs can have a negative impact on workers' labor-market outcomes, especially ethnic minorities. Building on Granovetter's idea that weak ties are superior to strong ties for providing support in getting a job, we develop a model in which workers who live far away from jobs tend to have less connections to weak ties. Because of the lack of good public transportation in the US, it is costly (both in terms of time and money) to commute to business centers to meet other types of people who can provide other source of information about jobs. If distant minority workers mainly rely on their strong ties, who are more likely to be unemployed, there is then little chance of escaping unemployment. It is therefore the separation in both the social and physical space that prevents ethnic minorities finding a job.
\end{abstract}

Keywords: Weak ties, labor market, social networks, land rent.

JEL Classification: A14, J15, R14, Z13.

*I'm grateful to Joan de Marti for helpful comments.

†Stockholm University and Research Institute of Industrial Economics (IFN), Sweden, and GAINS. Email: yves.zenou@ne.su.se. 


\section{Introduction}

There is ample evidence showing that distance to jobs is harmful to workers, in particular, ethnic minorities. This is known as the "spatial mismatch hypothesis". Indeed, first formulated by Kain (1968), the spatial mismatch hypothesis states that, residing in urban segregated areas distant from and poorly connected to major centres of employment growth, black workers face strong geographic barriers to finding and keeping well-paid jobs. In the US context, where jobs have been decentralized and blacks have stayed in the central parts of cities, the main conclusion of the spatial mismatch hypothesis is that distance to jobs is the main cause of high unemployment rates. Since Kain's study, hundreds of others have been conducted trying to test the spatial mismatch hypothesis (see, in particular, the literature surveys by Ihlanfeldt and Sjoquist, 1998; Ihlanfeldt, 2006; Zenou, 2008). The usual approach is to relate a measure of labor-market outcomes, typically employment or earnings, to another measure of job access, typically some index that captures the distance between residences and centres of employment. The general conclusions are: (a) poor job access indeed worsens labor-market outcomes, (b) black and Hispanic workers have worse access to jobs than white workers, and (c) racial differences in job access can explain between one-third and one-half of racial differences in employment.

Despite this huge empirical literature, few theoretical models have been proposed (for a survey on the theoretical literature, see Gobillon et al., 2007; Zenou, 2006b; 2009). The standard approach is to use a search model to show that distant workers tend to search less (due to lack of information about jobs or less opportunities to find a job) and thus stay longer unemployed (Coulson et al., 2001; Wasmer and Zenou, 2002).

In the present paper, we propose an alternative explanation. Building on Granovetter $(1973,1974,1983)$ 's idea that weak ties are superior to strong ties for providing support in getting a job, ${ }^{1}$ we develop a model in which workers who live far away from jobs tend to have less connections to weak ties. As underscored by Granovetter, in a close network where everyone knows each other, information is shared and so potential sources of information are quickly shaken down so that the network quickly becomes redundant in terms of access to new information. In contrast Granovetter stresses the strength of weak ties involving a secondary ring of acquaintances who have contacts with networks outside ego's network and

\footnotetext{
${ }^{1}$ In his seminal papers, Granovetter $(1973,1974,1983)$ defines weak ties in terms of lack of overlap in personal networks between any two agents, i.e. weak ties refer to a network of acquaintances who are less likely to be socially involved with one another. Formally, two agents A and B have a weak tie if there is little or no overlap between their respective personal networks. Vice versa, the tie is strong if most of A's contacts also appear in B's network.
} 
therefore offer new sources of information on job opportunities. ${ }^{2}$

Our explanation of the spatial mismatch is that distant (black) workers live in neighborhoods with closed networks that are limited in getting information about possible jobs. Because of the lack of good public transportation in the US, it is costly (both in terms of time and money) to commute to business centers to meet other types of people (weak ties) who can provide other source of information about jobs. If distant (black) workers mainly rely on their (black) strong ties and if the latter are unemployed, there is then little chance of escaping unemployment and finding a job. In other words, in our framework, ethnic minorities experience higher unemployment rate because they are separated both in the urban and the social space.

This is the first aim of our paper. The second aim is to provide a unified theory linking the urban and the social space. Indeed, social interactions are a key aspect of everyday's life. People interact with each other to exert social activities, exchange information about jobs, etc. These interactions, in particular in the labor market, tend to be localized. For instance, using Census Tract data for Chicago in 1980 and 1990, Topa (2001) finds a significantly positive amount of social interactions across neighboring tracts, especially for areas with a high proportion of less educated workers and/or minorities. Bayer et al. (2008) also document that people who live close to each other, defined as being in the same census block, tend to work together, that is, in the same census block. ${ }^{3}$ In order to understand the interactions between the labor and the land market and the role of social networks, a model incorporating all these elements is needed. Indeed, households make trade-offs among the opportunity for social interaction, commuting costs, and housing costs in deciding residential location. This, in turn, affects their opportunities in the labor market. The second aim of this paper is therefore to develop a model where social interaction, labor and land market aspects are all explicitly taken into account.

To be more precise, we consider a dynamic model of the labor market in which dyad members do not change over time so that two individuals belonging to the same dyad hold a

\footnotetext{
${ }^{2}$ The existing empirical evidence lends some support to Granovetter (1995)'s ideas. Yakubovich (2005) uses a large scale survey of hires made in 1998 in a major Russian metropolitan area and finds that a worker is more likely to find a job through weak ties than through strong ones. These results come from a within-agent fixed effect analysis, so are independent of workers' individual characteristics. Using data from a survey of male workers from the Albany NY area in 1975, Lin et al. (1981) find similar results. Lai et al. (1998) and Marsden and Hurlbert (1988) also find that weak ties facilitate the reach to a contact person with higher occupational status, who in turn leads to better jobs, on average. See also Patacchini and Zenou (2008) who find evidence of the strength of weak ties in crime.

${ }^{3}$ See also Ioannides and Topa (2010).
} 
strong tie with each other. However, each dyad partner can meet other individuals outside the dyad partnership, referred to as weak ties or random encounters. By definition, weak ties are transitory and only last for one period. The process through which individuals learn about jobs results from a combination of a socialization process that takes place inside the family (in the case of strong ties) and a socialization process outside the family (in the case of weak ties). ${ }^{4}$ Thus, information about jobs is essentially obtained through strong and weak ties and thus word-of-mouth communication. ${ }^{5}$ Workers commute to a business center to work and to interact with other people. We find that housing prices increase with the level of social interactions in the city because information about jobs is transmitted more rapidly and, as a result, individuals are more likely to be employed and to be able to pay higher land rents. We also show that workers using more their weak ties than strong ties to find a job receive a higher wage.

We then extend this framework by endogeneizing social interactions. We find that workers living far away from jobs pay lower housing prices but experience higher unemployment rates than those living close to jobs because they mainly rely on their strong ties to obtain information about jobs.

This last result is important because it allows us to provide a theoretical mechanism explaining why residents in certain neighborhoods may be stuck in high unemployment 'traps' since they mostly exchange information with their strong ties, who are themselves likely not to possess much useful information about job opportunities. Since most blacks in the United States tend to live further away from jobs (Ihlanfeldt and Sjoquist, 1998), then this model could explain why they have difficulty leaving unemployment. In our model, it is due to the fact that they mainly interact with their strong ties (other blacks) and very little with their weak ties (whites) so that their information about jobs is limited since blacks tend to be more unemployed and have poorer social networks than whites (see, e.g. Wial, 1991). This is related to Putman (2007) who finds that higher levels of ethnic homogeneity are associated with higher level of trust. ${ }^{6}$ In other words, blacks will not interact with

\footnotetext{
${ }^{4}$ This idea was first put forward by Bisin and Verdier $(2000,2001)$ in the context of the transmission of a trait like, for example, religion or identity.

${ }^{5}$ Resorting to word of mouth and newspaper ads are two major job-search methods used by unemployed workers (see e.g. Holzer, 1987, 1988; Wahba and Zenou, 2005). Word of mouth, in particular, seems to be of crucial importance: almost 70 percent of the jobs obtained by white workers and almost 60 percent of those obtained by black workers are found by checking with relatives or friends or through direct application without referral (Holzer, 1987). For a summary of the evidence, see Ioannides and Loury (2004) and Topa (2011).

${ }^{6}$ Other studies have also found that socioeconomic diversity is associated with lower level of trust (Alesina and la Ferrera, 2002; Glaeser et al., 2000). See the literature review by Costa and Kahn (2003).
} 
whites (and vice versa) because they do not trust each other. In our framework, they do not interact with each other because they are physically separated and, as a result, it is too costly for blacks to interact with whites (weak ties). Dawkins (2006) underscores this result by noticing that social networks may also influence the rate of residential mobility, if households are reluctant to move away from particular locations when local social ties are strong. We assume that strong ties are always of the same race (family, best friends) and there is no spatial costs of interacting with them because they tend to live in the same neighborhood. On the contrary, weak ties can be of either race and meeting them implies a commute to the center of activities. Our main result shows that a separation in the physical space (due, for instance, to housing discrimination) can have dramatic consequences for blacks' outcomes. In other words, even if black and white workers are totally identical in terms of income, commuting costs, job-information rate, job-destruction rate, etc., then if blacks are separated from whites in the geographical space by living further away from jobs, they will experience very different unemployment rates.

\section{Related literature}

There is a growing interest in theoretical models of peer effects and social networks (see e.g. Akerlof, 1997; Glaeser et al., 1996; Ballester et al., 2006; Calvó-Armengol et al., 2009), especially in the labor market. ${ }^{7}$ However, few models of social networks in the labor market are dynamic. Montgomery (1994) and Calvó-Armengol et al. (2007) propose a dynamic model of weak and strong ties but the former focuses on inequality while the latter on the interaction between crime and labor markets. Calvó-Armengol and Jackson (2004) have a more general network analysis (since they can encompass any network structure) but do not model the urban space. To the best of our knowledge, there are nearly no theoretical papers in which social interactions in the labor market are embedded in an urban space. ${ }^{8}$ An exception is Selod and Zenou (2006) but there is no explicit analysis of the social network.

In the present paper, we use the basic framework of Calvo-Armengol et al. (2007) to incorporate the urban space. Compared to this paper, we endogeneize wages, which allows us to derive a positive relationship between wages and social interactions, and social interactions, which allows us to establish a negative relationship between social interactions and distance to jobs. We also explicitly model the interactions between black and white workers in both the urban and social space. All these three new aspects are crucial to explain the stylized facts described at the beginning of this introduction. To the best of our knowledge, this is the first theoretical paper that explicitly models both the urban and the social space

\footnotetext{
${ }^{7}$ See the excellent literature review by Ioannides and Loury (2004).

${ }^{8}$ See Ioannides (2011, Chap. 5) who reviews the literature on social interactions and urban economics.
} 
in a unified framework. It has to be emphasized that this combination is difficult because social networks consider a finite number of individuals (Vega-Redondo, 2007; Goyal, 2007; Jackson, 2008) while the urban monocentric city model has a continuum of individuals (Fujita, 1989; Fujita and Thisse, 2002; Zenou, 2009). Our model can be seen a first step towards this direction. One the one hand, the network is extremely simplified since we only consider dyads, i.e., individuals belong to mutually exclusive two-person groups. On the other, because of dyads, we can develop a dynamic model, an essential feature of labor markets. ${ }^{9}$

\section{The model}

Consider a population of individuals of size one.

Dyads We assume that individuals belong to mutually exclusive two-person groups, referred to as dyads. We say that two individuals belonging to the same dyad hold a strong tie to each other. We assume that dyad members do not change over time. A strong tie is created once and for ever and can never be broken. Thus, we can think of strong ties as links between members of the same family, or between very close friends.

Individuals can be in either of two different states: employed or unemployed. Dyads, which consist of paired individuals, can thus be in three different states, ${ }^{10}$ which are the following:

(i) both members are employed - we denote the number of such dyads by $d_{2}$;

(ii) one member is employed and the other is unemployed $\left(d_{1}\right)$;

(iii) both members are unemployed $\left(d_{0}\right)$.

Aggregate state By denoting the employment rate and the unemployment rate at time $t$ by $e(t)$ and $u(t)$, where $e(t), u(t) \in[0,1]$, we have:

$$
\left\{\begin{array}{l}
e(t)=2 d_{2}(t)+d_{1}(t) \\
u(t)=2 d_{0}(t)+d_{1}(t)
\end{array}\right.
$$

\footnotetext{
${ }^{9}$ There are some recent papers that combine social interactions and urban spatial structure (Helsley and Strange, 2007; Brueckner and Lagey, 2008). However, in all these papers, the social network is not explicitly modelled. Social interactions are captured by externalities and only average effects are considered.

${ }^{10}$ The inner ordering of dyad members does not matter.
} 
The population normalization condition can then be written as

$$
e(t)+u(t)=1
$$

or, alternatively,

$$
d_{2}(t)+d_{1}(t)+d_{0}(t)=\frac{1}{2}
$$

Social interactions Time is continuous and individuals live for ever. We assume repeated random pairwise meetings over time. Matching can take place between dyad partners or not. At time $t$, each individual can meet a weak tie with probability $\omega(t)$ (thus $1-\omega(t)$ is the probability of meeting his strong-tie partner at time $t){ }^{11}$ In Sections 2 to 5 , we assume these probabilities to be constant and exogenous, not to vary over time and thus, they can be written as $\omega$ and $1-\omega$. We endogeneize $\omega$ in section 6 below. Observe that strong ties and weak ties are assumed to be substitutes, i.e. the more someone spends time with weak ties, the less he has time to spend with his strong tie.

We refer to matchings inside the dyad partnership as strong ties, and to matchings outside the dyad partnership as weak ties or random encounters. Within each matched pair, information is exchanged, as explained below. Observe that we assume symmetry within each dyad, that is if I meet a strong (or a weak) tie, then my strong (or weak) tie has to meet me. In the language of graph theory, this means that the network of relationships is undirected (Jackson, 2008).

Information transmission Each job offer is taken to arrive only to employed workers, who can then direct it to one of their contacts (through either strong or weak ties). This is a convenient modelling assumption, which stresses the importance of on-the-job information. ${ }^{12}$ The gist of the analysis would be preserved if this assumption is relaxed. To be more precise, employed workers hear of job vacancies at the exogenous rate $\lambda$ while they lose their job at the exogenous rate $\delta$. All jobs and all workers are identical (unskilled labor) so that all employed workers obtain the same wage. Therefore, employed workers, who hear about a job, pass this information on to their current matched partner, who can be a strong or a weak tie. Thus, information about jobs is essentially obtained through social networks.

\footnotetext{
${ }^{11}$ If each individual has one unit of time to spend with his friends, then $\omega(t)$ can also be interpreted as the percentage of time spent with weak ties.

${ }^{12}$ There is strong evidence that firms rely on referral recruitment (Bartram et al. 1995; Barber et al., 1999; Mencken and Winfield, 1998; Pellizzari, 2010) and it is even common and encouraged strategy for firms to pay bonuses to employees who refer candidates who are successfully recruited to the firm (Berthiaume and Parsons, 2006).
} 
This information transmission protocol defines a Markov process. The state variable is the relative size of each type of dyad. Transitions depend on labor market turnover and the nature of social interactions as captured by $\omega$. Because of the continuous time Markov process, the probability of a two-state change is zero (small order) during a small interval of time $t$ and $t+d t$. This means, in particular, that both members of a dyad cannot change their status at the same time. For example, two unemployed workers cannot find a job at the same time, i.e. during $t$ and $t+d t$, the probability assigned to a transition from a $d_{0}$-dyad to a $d_{2}$-dyad is zero. Similarly, two employed workers $\left(d_{2}-\right.$ dyad) cannot both become unemployed, i.e. switch to a $d_{0}-$ dyad during $t$ and $t+d t$. This applies to all other dyads mentioned above.

Flows of dyads between states It is readily checked that the net flow of dyads from each state between $t$ and $t+d t$ is given by:

$$
\left\{\begin{array}{l}
\dot{d}_{2}(t)=h(e(t)) d_{1}(t)-2 \delta d_{2}(t) \\
\dot{d}_{1}(t)=2 g(e(t)) d_{0}(t)-[\delta+h(e(t))] d_{1}(t)+2 \delta d_{2}(t) \\
\dot{d}_{0}(t)=\delta d_{1}(t)-2 g(e(t)) d_{0}(t)
\end{array}\right.
$$

where $h(e(t)) \equiv[1-\omega+\omega e(t)] \lambda$ and $g(e(t)) \equiv \omega e(t) \lambda$.

Let us explain in details these equations. Take the first one. Then, the variation of dyads composed of two employed workers $\left(\dot{d}_{2}(t)\right)$ is equal to the number of $d_{1}$-dyads in which the unemployed worker has found a job (through either his strong tie with probability $(1-\omega) \lambda$ or his weak tie with probability $\omega e(t) \lambda)$ minus the number of $d_{2}$-dyads in which one of the two employed workers has lost his job. In the second equation, the variation of dyads composed of one employed and one unemployed worker $\left(\dot{d}_{1}(t)\right)$ is equal to the number of $d_{0}$-dyads in which one of the unemployed workers has found a job (only through his weak tie with probability $g(e(t))$ since his strong tie is unemployed and cannot therefore transmit any job information) minus the number of $d_{1}$-dyads in which either the employed worker has lost his job (with probability $\delta$ ) or the unemployed worker has found a job with the help of his strong or weak tie (with probability $h(e(t))$ ) plus the number of $d_{2}$-dyads in which one the two employed has lost his job. Finally, in the last equation, the variation of dyads composed of two unemployed workers $\left(\dot{d}_{0}(t)\right)$ is equal to the number of $d_{1}$-dyads in which the employed worker has lost his job minus the number of $d_{0}$-dyads in which one of the unemployed workers has found a job (only through his weak tie, with probability $g(e(t))$ ) These dynamic equations reflect the flows across dyads. Graphically, 


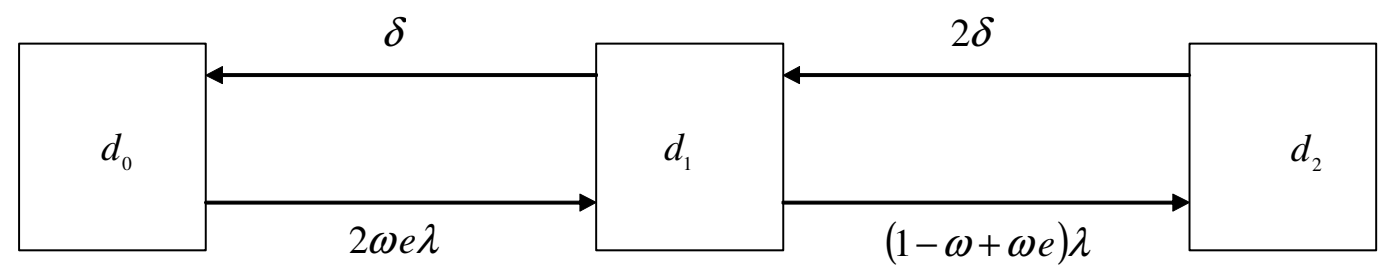

Figure 1: Flows in the labor market

Observe that the assumption stated above that both members of a dyad cannot lose their status at the same time is reflected in the flows described by (4). What is crucial in our analysis is that members of the same dyad (strong ties) always remain together throughout their life. So, for example, if a $d_{2}$-dyad becomes a $d_{0}$-dyad, the members of this dyad are exactly the same; they have just changed their employment status.

Taking into account (3), the system (4) reduces to a two-dimensional dynamic system in $d_{2}(t)$ and $d_{1}(t)$ given by:

$$
\left\{\begin{array}{l}
\dot{d}_{2}(t)=h(e(t)) d_{1}(t)-2 \delta d_{2}(t) \\
\dot{d}_{1}(t)=2 g(e(t))\left(1 / 2-d_{2}(t)-d_{1}(t)\right)-[\delta+h(e(t))] d_{1}(t)+2 \delta d_{2}(t)
\end{array}\right.
$$

where, using (1):

$$
e(t)=2 d_{2}(t)+d_{1}(t)
$$

\section{Steady-state equilibrium analysis}

A steady-state equilibrium requires solving simultaneously two problems:

(i) (steady state) labor flows (referred to as a labor market equilibrium);

(ii) a location and rental price outcome (referred to as an urban land use equilibrium)

For convenience, we expose first the steady-state labor market equilibrium and then the urban land use equilibrium.

\subsection{Labor-market equilibrium}

In a steady-state $\left(d_{2}^{*}, d_{1}^{*}, d_{0}^{*}\right)$, each of the net flows in (4) is equal to zero. Setting these net flows equal to zero leads to the following relationships:

$$
d_{2}^{*}=\frac{\left(1-\omega+\omega e^{*}\right) \lambda}{2 \delta} d_{1}^{*}
$$




$$
d_{1}^{*}=\frac{2 \omega e^{*} \lambda}{\delta} d_{0}^{*}
$$

where

$$
\begin{gathered}
d_{0}^{*}=\frac{1}{2}-d_{2}^{*}-d_{1}^{*} \\
e^{*}=2 d_{2}^{*}+d_{1}^{*} \\
u^{*}=1-e^{*}
\end{gathered}
$$

Definition 1 A steady-state labor market equilibrium is a four-tuple $\left(d_{2}^{*}, d_{1}^{*}, d_{0}^{*}, e^{*}, u^{*}\right)$ such that equations (5), (6), (7), (8) and (9) are satisfied.

Define $Z=(1-\omega) / \omega, B=\delta /(\lambda \omega)$. We have the following result.

\section{Proposition 1}

(i) There always exists a steady-state equilibrium $\mathcal{U}$ where all individuals are unemployed and only $d_{0}-$ dyads exist, that is $d_{2}^{*}=d_{1}^{*}=e^{*}=0, d_{0}^{*}=1 / 2$ and $u^{*}=1$.

(ii) If

$$
\frac{\delta}{\lambda}<\frac{\omega+\sqrt{\omega(4-3 \omega)}}{2}
$$

there exists a steady-state equilibrium $\mathcal{I}$ where $0<e^{*}<1$ is defined by

$$
e^{*}=\frac{B^{2}}{2 d_{0}^{*}}-B-Z>0
$$

$0<u^{*}<1$ by (9), and $0<d_{0}^{*}<1 / 2$ is the unique (feasible) solution of the following equation:

$$
-\frac{Z}{B} d_{0}^{* 2}-\frac{(1+Z)}{2} d_{0}^{*}+\left(\frac{B}{2}\right)^{2}=0
$$

Also, the other dyads are given by:

$$
\begin{gathered}
d_{1}^{*}=\frac{2 e^{*}}{B} d_{0}^{*} \\
d_{2}^{*}=\frac{\left(Z+e^{*}\right) e^{*}}{B^{2}} d_{0}^{*}
\end{gathered}
$$


If condition (10) holds, then an interior equilibrium always exists. Indeed, the jobdestruction rate $\delta$ has to be not too large and the job-contact rate $\lambda$ high enough for the interior equilibrium to exist. Otherwise, all workers will be unemployed and the steady-state equilibrium $\mathcal{U}$ will prevail. The latter is obviously uninteresting and, from now on, we only focus on the labor market equilibrium $\mathcal{I}$.

At this stage, it is interesting to study the impact of $\delta$ on $e^{*}$. First, it is easily verified that

$$
\frac{\partial d_{0}^{*}}{\partial \delta}=\frac{1}{\lambda \omega B}\left[\frac{2 Z d_{0}^{* 2}+B^{3}}{4 d_{0}^{*} Z+(1+Z) B}\right]>0
$$

since when the job-destruction rate $\delta$ increases, more people lose their jobs and the number of dyads $d_{0}^{*}$ increases. Second, if we differentiate (11), we obtain:

$$
\frac{\partial e^{*}}{\partial \delta}=\frac{1}{\lambda \omega}\left[\frac{B}{2 d_{0}^{* 2}}\left(2 d_{0}^{*}-\delta \frac{\partial d_{0}^{*}}{\partial \delta}\right)-1\right]
$$

and this sign is ambiguous. Indeed, when $\delta$ increases, two opposite forces are at work. Remember that $e^{*}=2 d_{2}^{*}+d_{1}^{*}$. When $\delta$ increases, there is a negative effect on both $d_{2}^{*}$ and $d_{1}^{*}$ since the two persons involve in the $d_{2}^{*}$-dyad and the employed person involved in the $d_{1}^{*}$-dyad have more chance to lose their jobs (see (4)). There is also a positive effect on $d_{1}^{*}$ since if one of the persons involves in the $d_{2}^{*}$-dyad loses his job, then the $d_{2}^{*}$-dyad becomes a $d_{1}^{*}$-dyad (see (4)), which increases the number of $d_{1}^{*}$-dyads. ${ }^{13}$

\subsection{Urban land-use equilibrium}

Consider a continuum of equally productive workers uniformly distributed along a linear and closed city. All land is owned by absentee landlords and all firms are exogenously located in the Business District (BD hereafter). The BD is a unique employment center located at one end of the linear city. In a centralized city, it corresponds to the Central Business District, whereas in a completely decentralized city, it represents suburban employment. Workers are risk neutral, optimally decide their place of residence between the BD and the other end of the city, and all consume the same amount of land (normalized to 1 for simplicity). Without loss of generality, the density of residential land parcels is taken to be unity, so that there are exactly $x$ units of housing within a distance $x$ from the BD. As stated above, the total population is normalized to 1 .

\footnotetext{
${ }^{13}$ If we further look at the impact of the job-information rate $\lambda$ on $e^{*}$, the effect is also ambiguous for the same reason. In Proposition 4 below, we also analyze the impact of weak ties $\omega$ on $e^{*}$.
} 
Each individual is identified with one unit of labor. Each employed worker goes to the BD to work and incurs a fixed monetary commuting cost $\tau$ per unit of distance. When living at a distance $x$ from the $\mathrm{BD}$, he also pays a land rent $R(x)$, consumes 1 unit of land and $z_{1}$ unities of the non-spatial composite good (which is taken as the numeraire so that its price is normalized to 1 ) and earns a wage $y$. The wage is assumed to be exogenous. ${ }^{14}$ For example, one could think of a minimum wage that is exogenously fixed by the government. The instantaneous (indirect) utility of an employed worker located at a distance $x$ from the $\mathrm{BD}$ is equal to:

$$
V_{1}(x)=y-\tau x-R(x)
$$

Unemployed workers have lower commuting costs than the employed workers. One way to justify this assumption is that the unemployed workers tend to use cheaper transport mode (public transit) than the employed workers (who are more likely to take their cars). ${ }^{15}$ Another justification is that the unemployed workers have a lower opportunity cost of time than the employed, which implies that their commuting costs are lower. As a result, we assume that the unemployed workers incur a commuting cost $s \tau$ per unit of distance, where $0<s \leq 1$. The instantaneous (indirect) utility of an unemployed worker residing at a distance $x$ from the BD is therefore equal to:

$$
V_{0}(x)=b-s \tau x-R(x)
$$

where $b<y$ is the unemployment benefit. We assume that $b$ is exogenously financed by taxpayers who reside elsewhere (for example absentee landlords).

We are now able to calculate the expected utility of each worker. To do that, as in Zenou (2006a), we assume perfect capital markets with a zero interest rate. ${ }^{16}$ As a result, workers engage in income smoothing as they cycle in and out of unemployment. Thus, workers save while employed and draw down their savings when out of work, with their consumption expenditure reflecting average income. This means that all workers have identical disposable incomes, equal to the average income over the job cycle. To compute this income, observe that a worker spends a fraction $e^{*}(\omega)=d_{1}^{*}+2 d_{2}^{*}$ of his time employed and a fraction

\footnotetext{
${ }^{14}$ This wage will be endogeneized in Section 5 below.

${ }^{15}$ For evidence on this, see e.g. Bhat (1997).

${ }^{16}$ When there is a zero interest rate, workers have no intrinsic preference for the present so that they only care about the fraction of time they spend employed and unemployed. Therefore, the expected utilities are not state dependent.
} 
$1-e^{*}(\omega)=2 d_{0}^{*}+d_{1}^{*}$ of his time unemployed. Therefore, the expected utility of a worker residing in $x$ is given by:

$$
E V(x)=e^{*}(\omega) V_{1}(x)+\left[1-e^{*}(\omega)\right] V_{0}(x)
$$

Using (15) and (16), this expected utility can be written as:

$$
E V(x)=e^{*}(\omega)(y-\tau x)+\left[1-e^{*}(\omega)\right](b-s \tau x)-R(x)
$$

where $e^{*}(\omega)$ is given by (11). Observe that, in order to write this expected utility, we have implicitly assumed that, because workers are able to smooth their income over time, a worker's residential location remains fixed as he enters and leaves unemployment. Other models have assumed that changes in employment status involve changes in residential location (Zenou, 2009). Which assumption is more relevant may depend on the nature of the labor market considered. When unemployment and employment spells are short (i.e. a U.S. style labor market), assuming that workers change their residential relocation as soon as they change job is not necessarily appealing. Indeed, even though residential mobility in the U.S. is quite high, ${ }^{17}$ only a small fraction $(5.6 \%)$ of people move within a county for job-related reasons (see Table 2 in Rupert and Wasmer, 2009). However, in a European context, long spells of employment and unemployment make it more likely that relocation and labor transitions coincide, in which case the assumption of absence of mobility costs would be relevant. In the present model, we have chosen the assumption of high-relocation costs because we have the US situation in mind.

Let us now solve the urban land use equilibrium. The timing is as follows. Assume that there is an initial situation when workers pick locations without knowing their initial employment status. They will not change location afterwards. Then, given zero discounting and income smoothing, people bid for rents given that they anticipate the time they will spend in each employment state. Thus, the whole structure of the analysis is: $(i)$ initial period location determination; ( $i$ i) ensuing labor market shocks resulting in unemployment, wage, etc. In equilibrium, because of the competition in the land/housing market, all ex ante identical workers will obtain the same expected utility $\overline{E V}$. It should be clear that the presence of high-relocation costs means that there is no bidding after initial location decisions.

We now need to calculate the bid rent of workers $\Psi(x, \overline{E V})$, which is defined as the maximum land rent that a worker is willing to pay at a given location $x$ so as to reach a

\footnotetext{
${ }^{17}$ Rosenthal (1988) shows that in the United States, the median renter moves roughly every one to two years, while the median homeowner moves every six to seven years. Even if it is not explained why people move, this shows a high level of residential mobility in the United States, at least for renters.
} 
given level of utility $\overline{E V}$. By solving (17) in $R(x)=\Psi(x, \overline{E V})$ for the utility level $\overline{E V}$, we easily obtain the following linear bid rent function:

$$
\Psi(x, \overline{E V})=e^{*}(\omega)(y-\tau x)+\left[1-e^{*}(\omega)\right](b-s \tau x)-\overline{E V}
$$

with

$$
\frac{\partial \Psi(x, \overline{E V})}{\partial x}=-\left[e^{*}(\omega)+\left[1-e^{*}(\omega)\right] s\right] \tau<0
$$

Indeed, in this model, bid rents compensate workers for their expected commuting costs. Those who live close to jobs pay higher land rents because they have lower pecuniary costs whether they are employed or not while those who live far away from jobs have the reverse. By normalizing the agricultural land to zero and by noticing that the size of the city is equal to 1 , we have the following definition:

Definition 2 An urban land-use equilibrium is a couple $\left(\overline{E V}^{*}, R^{*}(x)\right)$ such that:

$$
\begin{gathered}
\Psi\left(1, \overline{E V}^{*}\right)=0 \\
R^{*}(x)=\max \left\{\Psi\left(x, \overline{E V}^{*}\right), 0\right\}
\end{gathered}
$$

The first equation guarantees that the land rent is continuous everywhere in the city while the second equation is such that absentee landlords allocate land to the highest bidders. Solving (18) and (19) gives:

Proposition 2 At the urban land use equilibrium, we have:

$$
\overline{E V}^{*}=e^{*}(\omega)(y-\tau)+\left[1-e^{*}(\omega)\right](b-s \tau)
$$

and for $0 \leq x \leq 1$,

$$
R^{*}(x)=\left\{e^{*}(\omega)+\left[1-e^{*}(\omega)\right] s\right\} \tau(1-x)
$$

We can define the general equilibrium where both the steady-state interior labor and urban land-use equilibria are solved for simultaneously. Ignoring the equilibrium $\mathcal{U}$, we have the following result:

Proposition 3 If (10) holds, then there exists an interior steady-state equilibrium where the endogenous variables $\left(u^{*}, e^{*}, d_{0}^{*}, d_{1}^{*}, d_{2}^{*}, \overline{E V}^{*}, R^{*}(x)\right)$ are respectively determined by (9), (11), (12), (13), (14), (20) and (21). 


\section{Social interactions}

The most interesting results of this model is the impact of social interactions (captured by $\omega)$ on the different endogenous variables. We have a first important result.

Proposition 4 Assume

$$
\frac{\delta}{\lambda}<\sqrt{\frac{\omega}{6}}
$$

and consider steady-state equilibrium $\mathcal{I}$. Then, increasing the percentage of weak ties $\omega$ decreases both the number of $d_{0}-d y a d s$ and the unemployment rate $u^{*}$ in the economy, i.e.

$$
\frac{\partial d_{0}^{*}}{\partial \omega}<0 \quad, \quad \frac{\partial u^{*}}{\partial \omega}<0
$$

The effects of $\omega$ on $d_{1}^{*}$ and on $d_{2}^{*}$ are, however, ambiguous.

Proof. See the Appendix.

Here, individuals belong to mutually exclusive groups, the dyads, and weak tie interactions spread information across dyads. The parameter $\omega$ measures the proportion of social interaction that occurs outside the dyad, the inter-dyad interactions. When $\omega$ is high, the social cohesion between employed and unemployed workers is high and thus they are in close contact with each other. In this context, increasing $\omega$ induces more transitions from unemployment to employment and thus $u^{*}$, the unemployment rate in the economy decreases. This is true if (22) holds. ${ }^{18}$ This condition (22) also guarantees that (10) holds, i.e. that an interior steady-state equilibrium $\mathcal{I}$ exists (see the Appendix). Condition (22) states that the job-destruction rate $\delta$ has to be low enough while the job-contact rate $\lambda$ and social interactions $\omega$ have to be large enough. As a result, we are in a "reasonable" economy where jobs are not destroyed too fast and jobs are created at the sufficient high rate (otherwise we will end up with the steady-state equilibrium $\mathcal{U}$ where all workers are unemployed). Take our model and interpret the unit time as one quarter of a year. In the US, the sample average for the quarterly job destruction rate is $5.5 \%$ (Davis and Haltiwanger, 1992), thus $\delta=0.055$. We know from most studies that $\lambda=4$, which means that on average people hear from a job every three weeks. In that case, condition (22) is always satisfies even for very low values of $\omega$, like e.g. $\omega=0.01$.

Even though $u^{*}$ decreases, the effect of $\omega$ on $d_{2}^{*}$ and $d_{1}^{*}$ is ambiguous. Indeed, from Figure 1 , individuals leave dyad $d_{1}$ and enters dyad $d_{2}$ at rate $h(e) \equiv(1-\omega+\omega e) \lambda$. Since

$$
\frac{\partial[(1-\omega+\omega e) \lambda]}{\partial \omega}=\left(-1+e+\omega \frac{\partial e}{\partial \omega}\right) \lambda
$$

\footnotetext{
${ }^{18}$ Even if (22) does not hold, it can still be true since (22) is a sufficient condition.
} 
is ambiguous (because $-1+e<0$ ), the effects mentioned above are also ambiguous. Now consider the effect of $\omega$ on $d_{0}^{*}$. This is clearly negative. Indeed, from Figure 1, one can see that individuals leave dyad $d_{0}$ at rate $2 \omega e \lambda$. Since

$$
\frac{\partial(2 \omega e \lambda)}{\partial \omega}=2 \lambda\left(e+\omega \frac{\partial e}{\partial \omega}\right)>0
$$

then, when $\omega$ increases, there are fewer $d_{0}$-dyads.

Proposition 5 Assume (22) and consider steady-state equilibrium $\mathcal{I}$. Then, increasing the percentage of weak ties $\omega$ increases both the price of land (and housing) everywhere in the city and the utility level of all workers, i.e.

$$
\begin{gathered}
\frac{\partial R^{*}(x)}{\partial \omega}>0, \forall x \in[0,1] \\
\frac{\partial \overline{E V}^{*}}{\partial \omega}>0
\end{gathered}
$$

Indeed, when the strength of weak ties $\omega$ increases, people find jobs more easily and thus spend more time employed during their lifetime. As a result, there are able to bid more for land and thus the competition in the land market becomes fiercer. Consequently, the price of housing increases at each location in the city. Because the positive impact of $\omega$ on employment is large enough to outweigh the negative effect of the land rent, the expected utility increases with an increase in $\omega$. The effect of weak ties on the land rent is an interesting and new result. It is though simple and intuitive since it says that if there are more social interactions in an area, then information about jobs is transmitted more rapidly and, as a result, more people would be employed and land rents would be higher. ${ }^{19}$

In the broader context of the search literature, the results of Proposition 5 illustrate the fact that anything that reduces search frictions in the labor market is going to increase employment and hence expected incomes and land rents. The interesting feature here is that it makes this connection explicit in the specific context of labor market referrals.

\footnotetext{
${ }^{19}$ There is a recent paper by $\mathrm{Fu}(2005)$ who tests in some sense this result. Fu (2005) uses the 1990 Massachusetts census data and estimates hedonic housing model with social amenities. He found that an increase in the percentage of new residents has significant positive effects on property values. He concludes that this is "probably due to the strength of weak ties". Of course, it could also be consistent with other aspects such as, for example, gentrification. The results of a direct empirical test of the impact of social interactions on land rents will be very interesting and will help us to verify if the prediction of our model is correct.
} 
In Section 6 below, we show that the results of Proposition 5 hold across different neighborhoods or different ethnic groups that may differ in their prevalence of weak versus strong ties. Indeed, we show that workers living further away from jobs have lower interactions with weak ties, and, as a result, spend less time employed. This, in turn, implies that they pay lower land rents as compared to those residing closer to jobs. Since black workers tend to live further away from jobs than other ethnic groups, especially whites, this could explain why they are less likely to be employed and pay lower rents. To show that they experience lower expected utility, it suffices to introduce some heterogeneity, like e.g. discrimination or difference in human capital. ${ }^{20}$

\section{Endogenous wages}

In this section, we endogenously determine the wage $y$. For that, we use an efficiency wage model (Shapiro and Stiglitz, 1984) where firms set wages to deter shirking. There are only two possible effort levels: either the worker shirks, exerts zero effort, $a=0$, and contributes to zero production, or he does not shirk, provides full effort, $a>0$, and contributes to 1 unit of production.

On the incentive mechanism of the efficiency wage model, there is plenty of empirical evidence. Basically this model stipulates that employees are rational cheaters who anticipate the consequences of their actions and shirk when the marginal benefit exceeds the costs, and firms respond to this decision calculus by implementing monitoring and incentive pay policies (i.e. efficiency wage) that make shirking unprofitable. Cappelli and Chauvin (1991) find that higher wage premiums are associated with lower levels of shirking, as measured by disciplinary dismissals. Using data from the US National Longitudinal Survey of Youth (NLSY) in 1992, Goldsmith et al. (2000) find that receiving an efficiency wage enhances an individual's effort and that individuals providing a greater effort earn higher wages. ${ }^{21}$ Recent research has used a natural experiment setting in which monitoring levels are exogenously varied across similar sites and substantial resources are devoted to tracking the behavior of employees. Fehr et al. (1996) were the first to use a natural experiment and show that higher wages indeed sharply reduce shirking. More recently, Nagin et al. (2002) propose another experiment by collecting data from a large telephone solicitation company. They show that a significant fraction of employees behave according to the predictions of the shirking model.

\footnotetext{
${ }^{20}$ We discuss these ethnic issues in detail in Section 7.

${ }^{21}$ See also Rebitzer (1995), who finds that high levels of supervision are associated with lower wage levels, and Strobl and Walsh (2007), which results indicate a positive relationship between monitoring and effort.
} 
Specifically, they find that these employees respond to a reduction in the perceived cost of opportunistic behavior by increasing the rate at which they shirk. ${ }^{22}$

As before, there is a stochastic process in employment status changes. However, firms cannot perfectly monitor workers, so there is a rate at which shirking is detected, denoted by $m$ (i.e. monitoring rate). If a worker is caught shirking, he is automatically fired. As a result, for non-shirkers, the stochastic process is as before and described by Figure 1. However, for shirkers, it is as in Figure 1 with one difference: $\delta$ is replaced by $\delta+m$, since shirkers can lose their jobs either because there is a technological shock that leads to the destruction of the job or because the worker has been caught shirking and fired. The rest of the stochastic process is exactly the same as in the previous section. In particular, the way workers find a job and transmit information within and outside the dyad is the same. As a result, the employment rate for non-shirkers, $e^{*}(\omega)=e^{N S}(\omega)$ is still given by (11), while that of shirkers $e^{S *}(\omega)$ is defined by (11), where $\delta$ is replaced by $\delta+m$.

We can now write the expected utilities. For a non shirker located at a distance $x$ from the $\mathrm{BD}$, his expected utility is equal to:

$$
E V^{N S}(x)=e^{*}(\omega)(y-a-\tau x)+\left[1-e^{*}(\omega)\right](b-s \tau x)-R(x)
$$

whereas, for a shirker residing at a distance $x$ from the $\mathrm{BD}$, it is given by:

$$
E V^{S}(x)=e^{S *}(\omega)(y-\tau x)+\left[1-e^{S *}(\omega)\right](b-s \tau x)-R(x)
$$

The trade off between shirking and non shirking is clear: shirkers do not provide effort $a$ but spend more time unemployed. Let us calculate the efficiency wage. Firms know that workers have a zero discount rate, so, at each $x$, they solve $E V^{N S}(x)=E V^{S}(x)$. By using (23) and (24), we easily obtain the following efficiency wage:

$$
y^{e f f}=b+a \frac{e^{*}(\omega)}{\left[e^{*}(\omega)-e^{S *}(\omega)\right]}+(1-s) \tau x
$$

Equation (25) is also referred to as the non-shirking condition. The information available to firms about workers' residence matters in the process of wage formation. If firms perfectly observe the residential location of all workers, then they will set the wage (25) at each location $x$. In firms do not perfectly observe the residential location of all workers in the city, then, to prevent shirking, they will set the highest possible wage, i.e. the one for the

\footnotetext{
${ }^{22}$ There is a recent paper by Fehr and Goette (2007) using an experiment in a laboratory that shows that workers work more when wages are higher.
} 
worker located at the city fringe $x=1$. In that case, the efficiency wage for all workers will be given by:

$$
y^{e f f}=b+a \frac{e^{*}(\omega)}{\left[e^{*}(\omega)-e^{S *}(\omega)\right]}+(1-s) \tau
$$

This is the case we consider now, ${ }^{23}$ i.e. firms do not have perfect information on workers' residence. $^{24}$ This efficiency wage has the standard properties of non-spatial models (Shapiro and Stiglitz, 1984). Indeed, when $b, a$, or $\delta$ increases, or $m$ decreases (these are the nonspatial effects), the efficiency wage has to increase in order to prevent shirking. The spatial aspect of the wage is determined by the positive relationship between (efficiency) wages and commuting costs. Indeed, when someone shirks, only the gain in commuting costs is (positively) affected by $x$, the distance to jobs. So, the further away from the BD a worker resides, the higher the benefit of shirking in terms of commuting costs. As a result, if firms want to induce workers not to shirk at each $x$, they have to increase the wage for workers living further away from jobs in order to exactly compensate the additional gain from shirking, that is $(1-s) \tau x$. In the case of imperfect information, the spatial compensation is for the worker located at $x=1$ and it is thus equal to $(1-s) \tau$.

What is new in the present model is the impact of social interactions $\omega$ on wages. The term $\frac{e^{*}(\omega)}{e^{*}(\omega)-e^{S *}(\omega)}$ captures the incentive aspect of the efficiency wage, ${ }^{25}$ i.e. the amount necessary to prevent shirking. As in Shapiro and Stiglitz (1984), it is a function of employment (or unemployment) since unemployment acts as a worker discipline device. Denote $\Delta e^{*} \equiv \frac{e^{*}(\omega)-e^{S *}(\omega)}{e^{*}(\omega)}>0$, i.e. the difference in employment rates between shirking and nonshirking behaviors, then

$$
y^{e f f}=b+\frac{a}{\Delta e^{*}}+(1-s) \tau
$$

Indeed, the higher the difference in employment rate between shirking and non-shirking behaviors, the less workers are induced to shirk, and the lower is the efficiency wage needed to reduce shirking. Define

$$
\eta_{\omega}^{N S} \equiv \frac{\partial e^{*}(\omega)}{\partial \omega} \frac{\omega}{e^{*}(\omega)}>0
$$

as the elasticity of non-shirking employment with respect to weak ties and

$$
\eta_{\omega}^{S} \equiv \frac{\partial e^{S *}(\omega)}{\partial \omega} \frac{\omega}{e^{S *}(\omega)}>0
$$

\footnotetext{
${ }^{23}$ The case of perfect infomation is straightforward to analyze.

${ }^{24}$ It is also the more realistic case since workers can misreport their residential address.

${ }^{25}$ Observe that, by definition, $e^{*}(\omega)>e^{S *}(\omega)$.
} 
as the elasticity of shirking employment with respect to weak ties. We have the following result:

Proposition 6 Assume (22) and consider steady-state equilibrium $\mathcal{I}$. Then

$$
\frac{\partial y^{e f f}}{\partial \omega} \gtreqless 0 \Leftrightarrow \eta_{\omega}^{N S} \lesseqgtr \eta_{\omega}^{S}
$$

When interactions with weak ties $\omega$ increase, whether they shirk or not, workers are on average more employed over their lifecycle. However, if the responsiveness of employment to $\omega$ is higher for shirkers than non-shirkers, then firms need to increase the efficiency wage to deter shirking. This is an interesting result because it links social interactions and wages. In particular, it says that, if workers use more their weak ties than strong ties (strong ties than weak ties) to find a job, then they will receive higher wages if the elasticity of shirking (non-shirking) employment with respect to weak ties is higher than that of non shirking (shirking).

If we look at the empirical literature, the following relationship has been tested: do people who got their job through social contacts earn more or less than their peers who found a job using formal methods? The empirical results are not clear. Using data from across Europe and from three US cities (Boston, Atlanta and Los Angeles), Bentolila et al. (2010) found that, on average, people who obtained their job through social contacts find work more quickly but earned about 5 to 7 per cent less than their peers. Using the same data but looking at this relationship country by country, Pellizzari (2010) found that informal search channels lead to significantly better paying jobs in Austria, Belgium and the Netherlands, while the opposite is true in Greece, Italy, Portugal and the United Kingdom. In the other EU countries - and in the US - no significant wage difference is observed.

In all these studies, however, one cannot distinguish between weak and strong ties since social contacts are measured by "family, friends or other contacts". Our model predicts that the effects of strong and weak ties on wages are, in fact, different. There is some empirical evidence showing that the use of weak ties in job search tends to lead to higher wage outcomes (Granovetter, 1974), but the evidence is not very robust. Green et al. (1995) find that incomes are lower for those who use within-neighborhood ties, or ties to relatives, which, as in our model, tend to be strong rather than weak links. Green et al. (1999) find that the use of strong ties is negatively associated with annual earnings, especially for Hispanics. Bridges and Villemez (1986) also find that weak ties are linked to higher incomes than strong ties; however, the income effect of tie strength is greatly reduced when controls are added for education, experience, race, and gender. 
Our model also provides a new mechanism explaining this relationship. Indeed, previous theoretical research on the role of contacts in the labor market emphasizes that people may have higher wages because they inform the employer about the worker (Saloner, 1985; Montgomery, 1991), because they allow workers to more effectively sample a given wage distribution (Mortensen and Vishwanath, 1994; Calvó-Armengol and Jackson, 2004; 2007), or because they provide a cheaper search channel (Holzer, 1988). Bentolila et al. (2010) propose another type of model that emphasizes the fact that workers may sacrifice their productive advantage so as to find a job more easily, which can explain why jobs found through social contacts exhibit a wage reduction rather than a premium. Our mechanism is different since it is based on the possibility of shirking behavior by workers and how the employment of shirkers and non-shirkers react to an increase in the use of weak ties in finding a job.

As in the standard efficiency wage model, we can close the model by modelling the behavior of firms. Consider $M$ identical firms $(j=1, \ldots, M)$ in the economy. All firms produce the same composite good and sell it at a fixed market price $p$ (this good is taken as the numeraire and its price $p$ is set to 1 ). Firms only care of workers' productivity on the job and their main objective is to prevent shirking because it is very costly (workers produce nothing if they shirk). ${ }^{26}$ On the contrary, each worker, whatever his location, contributes to one unit of production if he does not shirk (which will always be true in equilibrium). The production function of each firm $j$ is: $F\left(l_{j}\right)$ and it is assumed that $F(\cdot)$ is twice differentiable, with $F(0)=0, F^{\prime}(\cdot)>0$ and $F^{\prime \prime}(\cdot) \leq 0$, and it satisfies the Inada conditions, i.e. $F^{\prime}(0)=+\infty$ and $F^{\prime}(+\infty)=0$.

Since all firms are identical, let us focus on a symmetric (steady-state) equilibrium in which each firm employs the same number of workers. This means that each firm $j$ hires $L_{j}=L=e^{*}(\omega) / M$ workers, where $e^{*}(\omega)$ is given by (11). As a result, each firm adjusts employment until the marginal product of an additional worker equals the efficiency wage (26). We obtain:

$$
b+a \frac{L^{*} M}{L^{*} M-e^{S}(\omega)}+(1-s) \tau=F^{\prime}\left(L^{*}\right)
$$

Because of the assumptions made on the production function, it is easy to show that there exists a unique solution in $L^{*}$. Because $L^{*}=e^{*}(\omega) / M$, and $e^{*}(\omega)$ is given by (11), $M$ will adjust so that $L^{*}=e^{*}(\omega) / M$ will be always true in equilibrium.

\footnotetext{
${ }^{26}$ Because $\omega$ has an impact on the efficiency wage, one could argue that firms could hire people depending on how they find a job. We assume that firms do not know if workers have found a job through their weak or strong ties. As a result, when deciding wage and employment, each firm takes $\omega$ as given.
} 


\section{Social interactions and distance to jobs}

We would like now to endogeneize $\omega$ and to provide a new mechanism explaining why distance to jobs can lead to adverse labor-market outcomes. We first postulate a negative relationship between $\omega$ and distance to jobs $x$. We will then derive this relationship endogenously by letting workers choosing optimally $\omega$. In this section, for simplicity, we will consider the wage $y$ as exogenous. Making it endogenous as in the previous section will not change any of our main results but will make the analysis more cumbersome.

\subsection{Exogenous relationship between weak ties and distance to jobs}

It should be clear that the relationships with strong ties are, in general, stronger closer to where people live while relationships with weak ties are more intense closer to business and shopping centers (see, for example, Ioannides and Topa, 2010). To capture these ideas, it is now assumed that $\omega$ is a decreasing function of $x$, i.e. $\omega(x)$ with $\omega^{\prime}(x)<0 .{ }^{27,28}$ As expressed by Glaeser (2000), "social influences decay rapidly with distance". For example, Topa (2001) and, more recently, Bayer et al (2008) found evidence of significant social interactions operating at the block level. ${ }^{29}$ In our model, these are interactions between strong ties since they are repeated over time. On the contrary, having contact with weak ties, defined as relationships with random encounters that are not repeated over time, are more likely to take place in dense and animated areas. We assume here that $\omega^{\prime}(x)<0$, meaning that there are more interactions in the business district (BD) with weak ties than further away from the BD. ${ }^{30}$ Sigelman et al. (1996), for the US, show that most superficial encounters occur while shopping, going to bars, and the like. So, basically, the closer people are from the business district, the more likely they interact with random encounters (weak ties). Similarly, Holland et al. (2007) show that public places located in the center of London (UK), are important areas of social interactions. In particular, social mixing takes place there where people of different income and ethnic groups tend to interact with each other. Also,

\footnotetext{
${ }^{27}$ We can further assume that $\omega(1)=0$ and $\omega(0)=1$, which implies that, at the $\mathrm{BD}(x=0)$, individuals interact only with weak ties while at the city fringe $(x=1)$, they interact only with strong ties. This is not necessary for our main results.

${ }^{28}$ In section 6.2 below, $\omega$ will be endogeneously chosen by individuals and we will show under which condition $\omega$ is a negative function of $x$.

${ }^{29}$ See also Kan (2007) who shows social capital to be very local.

${ }^{30}$ Using a different model, Helsey and Strange (2007) model social interactions in a more "extreme" way since all social interactions occur at a single location (the "center") and are defined as the number of visits to the center.
} 
Henning and Lieberg (1996) investigate the structure of networks and the content of ties in selected neighborhoods in Linköping, Sweden. Strong ties were those of importance to the respondent and which were characterized by regular contact. Weak ties consisted of nodding acquaintances and conversational contacts. Henning and Lieberg found that neighborhood where people live was relatively unimportant in weak ties relationships for both white-collar and blue-collar residents - three quarters of contacts were outside the local area. All this evidence indicate that interactions with weak ties do not take place where people reside but rather close to business and shopping centers.

In that case, Proposition 1 is exactly as before with one difference, which is that all endogenous variables (i.e. $u^{*}, e^{*}, d_{0}^{*}, d_{1}^{*}$ and $d_{2}^{*}$ ) are now a function of $x$ and not of $\omega$ (and of course a function of all the other exogenous variables). In particular, this means that, if condition (22) holds, then:

$$
\begin{aligned}
& \frac{\partial d_{0}^{*}}{\partial x}=\frac{\partial d_{0}^{*}}{\partial \omega} \frac{\partial \omega}{\partial x}>0 \\
& \frac{\partial u^{*}}{\partial x}=\frac{\partial u^{*}}{\partial \omega} \frac{\partial \omega}{\partial x}>0
\end{aligned}
$$

Indeed, for individuals living far away from jobs, it is less likely for them to meet weak ties who can provide information about jobs. So, for example, if someone is unemployed and belongs to a $d_{0}$-dyad, then the only persons who can provide information about jobs are weak ties. But if this person lives far away from the BD, he will not be very much in contact with weak ties, and therefore will have little information about jobs.

In that case, the expected utility can be written as:

$$
E V(x)=e^{*}(x)(y-\tau x)+\left[1-e^{*}(x)\right](b-s \tau x)-R(x)
$$

and thus the bid rent function is given by:

$$
\Psi(x, \overline{E V})=e^{*}(x)(y-\tau x)+\left[1-e^{*}(x)\right](b-s \tau x)-\overline{E V}
$$

This bid rent is not anymore linear. Indeed, we have:

$$
\frac{\partial \Psi(x, \overline{E V})}{\partial x}=\frac{\partial e^{*}(x)}{\partial x}[y-b-(1-s) \tau x]-(1-s) \tau e^{*}(x)-s \tau
$$

which is strictly negative since $0<e^{*}(x)<1$ and $e^{*}(x)=1-u^{*}(x), \forall x \in[0,1]$. The role of the land rent is now to compensate remote locations for both higher commuting costs and higher unemployment rates.

Adopting the same definition of equilibrium as in Definition 2, we obtain: 
Proposition 7 At the urban land use equilibrium where social interactions $\omega$ is a function of distance to jobs $x$, we obtain:

$$
E V^{*}=e^{*}(1)(y-\tau)+\left[1-e^{*}(1)\right](b-s \tau)
$$

and for $0 \leq x \leq 1$,

$$
R^{*}(x)=e^{*}(x)[y-b-(1-s) \tau x]-e^{*}(1)[y-b-(1-s) \tau]+s \tau(1-x)
$$

We can then solve the labor-market equilibrium as before. The dynamic system is given by:

$$
\left\{\begin{array}{l}
\dot{d}_{2}(t)=h(e(t)) d_{1}(t)-2 \delta d_{2}(t) \\
\dot{d}_{1}(t)=2 g(e(t)) d_{0}(t)-[\delta+h(e(t))] d_{1}(t)+2 \delta d_{2}(t) \\
\dot{d}_{0}(t)=\delta d_{1}(t)-2 g(e(t)) d_{0}(t)
\end{array}\right.
$$

where $h(e(t)) \equiv[1-\bar{\omega}+\bar{\omega} e(t)] \lambda$ and $g(e(t)) \equiv \bar{\omega} e(t) \lambda$ and where

$$
\bar{\omega}=\int_{0}^{1} \omega(x) d x
$$

So the only difference with the previous sections is that, when calculating the aggregate flows in the labor market, we use the average time workers spend with their weak ties, that is $\bar{\omega}$. In Section 7, when we introduce black and white workers, we fully develop this approach.

To summarize, when the relationship to weak ties is decreasing with distance to jobs, individuals who are close to the BD obtain a lot of information about jobs, spend little time in a $d_{0}$-dyad (where both friends are unemployed) and experience low unemployment rate. On the contrary, those who live far away from jobs spend most of their time with strong ties and thus get little information from weak ties. This means that when they belong to a $d_{0}$-dyad, where their best friend is also unemployed, they have little chance of finding a job and are stuck in the unemployment state. This is why they experience higher unemployment rates.

\subsection{Choosing social interactions}

We would like now to extend the model so that $\omega$ is chosen by individuals and not exogeneously defined as in the previous sections. The timing is as in the previous section. We assume that there is some cost of interacting with weak ties. Let $c$ denotes the marginal 
cost of these interactions. The expected utility is still given by (17) but we need to add the interaction costs. We have:

$$
E V(\omega, x)=e^{*}(\omega)(y-\tau x)+\left[1-e^{*}(\omega)\right](b-s \tau x)-R(x)-c \omega
$$

where $e^{*}(\omega)$ is defined by (11). Each individual optimally chooses $\omega$ that maximizes $E V(\omega, x)$. The first-order condition yields:

$$
\frac{\partial E V(\omega, x)}{\partial \omega}=\frac{\partial e^{*}(\omega)}{\partial \omega}[y-b-(1-s) \tau x]-c=0
$$

We assume that the second order condition always holds, i.e.

$$
\frac{\partial^{2} e^{*}(\omega)}{\partial \omega^{2}}<0
$$

Observe that $y-b-(1-s) \tau x>0, \forall x \in[0,1]$, and we have seen (see Proposition 4) that if (22) holds, then $\frac{\partial e^{*}(\omega)}{\partial \omega}>0$. We have the following result:

Proposition 8 Assume (22) and consider steady-state equilibrium $\mathcal{I}$. Then there exists a unique interior $\omega^{*}$ that maximizes $E V(\omega, x)$ and

(i) workers living further away from jobs will interact less with weak ties than those residing closer to jobs, i.e.

$$
\frac{\partial \omega^{*}}{\partial x}<0
$$

(ii) higher wages or lower unemployment benefits will increase the interactions with weak ties, i.e.

$$
\frac{\partial \omega^{*}}{\partial y}>0 \quad \frac{\partial \omega^{*}}{\partial b}<0
$$

(iii) higher commuting costs will decrease the interactions with weak ties, i.e.

$$
\frac{\partial \omega^{*}}{\partial \tau}<0
$$

Workers want to interact with weak ties because it increases their probability to be employed (or, equivalently, the time they spend employed during their lifetime), i.e. $\frac{\partial e^{*}(\omega)}{\partial \omega}>$ 0 . However, because it is always more expensive to commute to the business district when employed than when unemployed (i.e. $\tau>s \tau$ ), the marginal gain of interacting with weak ties is higher for workers residing closer to jobs than for those locating further away. To be more precise, when $x$ increases, the (spatial) cost of employment, $(1-s) t x$, increases while 
the gain of employment decreases at the margin since $\frac{\partial^{2} e(\omega)}{\partial \omega^{2}}<0$. As a result, people living further away from jobs find it optimal to interact less with weak ties and more with their strong ties.

Concerning wage $y$ and unemployment benefit $b$, a higher $y$ or $b$ increases the value of employment and, since $e^{*}(\omega)$ and $\omega$ are positively related, workers will interact more with weak ties. The same intuition applies for commuting costs $\tau$.

The model can be closed as in the previous section. What is interesting is that all endogenous variables are now a function of $x, y, b, \tau$. In particular,

$$
\begin{aligned}
& \frac{\partial u^{*}}{\partial x}=\frac{\partial u^{*}}{\partial \omega} \frac{\partial \omega}{\partial x}>0 \\
& \frac{\partial u^{*}}{\partial b}=\frac{\partial u^{*}}{\partial \omega} \frac{\partial \omega}{\partial b}>0 \\
& \frac{\partial u^{*}}{\partial \tau}=\frac{\partial u^{*}}{\partial \omega} \frac{\partial \omega}{\partial \tau}>0
\end{aligned}
$$

As before, workers residing further away will spend more time unemployed over their lifecycle. Also, higher unemployment benefits or commuting costs leads to higher unemployment. These results are conformed to the intuition, even though the mechanisms are new.

\section{Spatial mismatch and the strength of weak ties}

We would like now to extend our model to incorporate black and white workers and to analyze the impact of segregation in the physical and social space on their labor-market outcomes.

\subsection{The model}

There is a continuum of black and white workers whose mass is given by $N_{B}$ and $N_{W}$, with $N_{B}+N_{W}=N{ }^{31}$ We use here the model of Section 6.1 where it was assumed that $\omega$ is a decreasing function of $x$, i.e. $\omega(x)$ with $\omega^{\prime}(x)<0$. In other words, we do not endogeneize wages (as in Section 5) and do not derive the relationship between $\omega$ and $x$ (as in Section 6.2). The model is getting quite complicated so to keep it tractable we only use its main ingredients.

As before, individuals belong to dyads. We assume that strong ties are always of the same race (family, best friends) and there is no spatial costs of interacting with them ${ }^{32}$ because

\footnotetext{
${ }^{31}$ Subscripts $B$ and $W$ stand for "Black" and "White".

${ }^{32}$ As highlighted in Section 6.2, there can be social costs of interacting with strong ties.
} 
they tend to live in the same neighborhood. On the contrary, weak ties can be of either race and meeting them implies a commute to the center of activities, here the BD. By denoting the employment level and the unemployment level of workers of type $j=B, W$ at time $t$ by $E_{j}(t)$ and $U_{j}(t)$, we have:

$$
\left\{\begin{array}{l}
E_{j}(t)=2 d_{2 j}(t)+d_{1 j}(t) \\
U_{j}(t)=2 d_{0 j}(t)+d_{1 j}(t)
\end{array}\right.
$$

The population condition can then be written as

$$
E_{j}(t)+U_{j}(t)=N_{j}
$$

As before, we denote the employment rate and the unemployment rate of workers of type $j=B, W$ at time $t$ by $e_{j}(t)$ and $u_{j}(t)$, where $e_{j}(t), u_{j}(t) \in[0,1], \forall j \in\{B, W\}$. We have:

$$
e_{j}(t)=\frac{E_{j}(t)}{N_{j}}, u_{j}(t)=\frac{N_{j}-E_{j}(t)}{N_{j}}
$$

which means that

$$
u_{j}(t)=1-e_{j}(t)
$$

or, alternatively,

$$
d_{2 j}(t)+d_{1 j}(t)+d_{0 j}(t)=\frac{N_{j}}{2}
$$

As in the previous sections, each job offer is taken to arrive only to employed workers, who can then direct it to one of their contacts (through either strong or weak ties). Employed workers (black or white) hear of job vacancies at the exogenous rate $\lambda$ while they lose their job at the exogenous rate $\delta .^{33}$ Employed workers, who hear about a job, pass this information on to their current matched partner, who can be a strong or a weak tie. White (black) employed workers pass the job information to their white (black) strong tie and to any (white or black) weak tie.

We need to solve simultaneously the land/housing market and the labor market. In this section, it is more convenient to solve first the urban land use equilibrium and then the steady-state labor market equilibrium.

\footnotetext{
${ }^{33}$ We could have assumed that $\lambda$ is race specific so that $\lambda_{W}>\lambda_{B}$, i.e. whites hear more about job opportunities than blacks because they are better connected ("old boy" networks). This will just reinforce our results.
} 


\subsection{Urban land use equilibrium}

We assume that blacks face housing discrimination in the housing market, as documented by Yinger $(1986,1997)$. To keep the model tractable, the analysis focuses on a situation where housing discrimination is so strong that landlords in the area close to the BD refuse to rent to blacks under any circumstances. In other words, blacks are prevented from living in the interval $\left[0, N_{W}\right]$ regardless of their willingness to pay for land in this area. The resulting "restricted" residential pattern and the associated bid-rent curves are shown in Figure 2. ${ }^{34}$

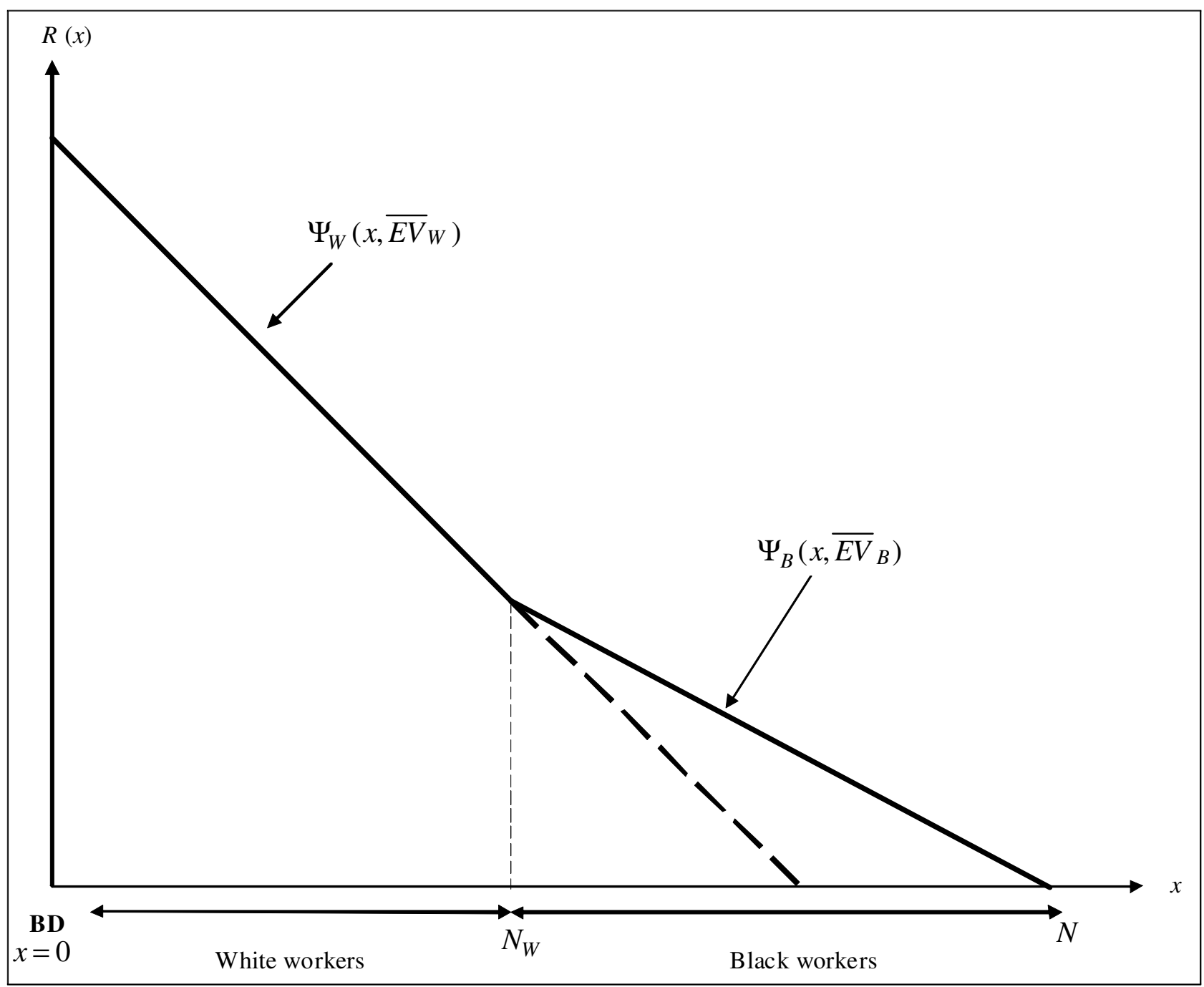

Figure 2: Urban-land use equilibrium with black and white workers

\footnotetext{
${ }^{34}$ We could have obtained a similar urban configuration by, for example, assuming that whites have higher income than blacks so that their time transportation costs will be higher than those of black workers.
} 
Using the same analysis as above, the expected utility of a worker of type $j=B, W$ can be written as:

$$
E V_{j}(x)=e_{j}^{*}(x)(y-\tau x)+\left[1-e_{j}^{*}(x)\right](b-s \tau x)-R(x)
$$

As can be seen from this equation, blacks and whites are totally identical in terms of income, transport costs, housing consumption, etc. ${ }^{35}$ The only difference between the two types of workers is due to the fact that blacks are discriminated against in the housing market while whites are not. The bid rent function of a type $-j$ individual is then given by:

$$
\Psi_{j}\left(x, \overline{E V}_{j}\right)=e_{j}^{*}(x)(y-\tau x)+\left[1-e_{j}^{*}(x)\right](b-s \tau x)-\overline{E V}_{j}
$$

As before, these bid rents are decreasing and non-linear. Since

$$
\frac{\partial e^{*}}{\partial \omega} \frac{\partial \omega}{\partial x}<0
$$

then workers living further away from jobs will experience lower employment rates and thus, on average, higher commuting costs. This means that whites' bid rents are steeper than blacks' bid rents. We can now define the urban land-use equilibrium as follows:

Definition 3 An urban-land use equilibrium with black and white workers is a 3-tuple $\left(\overline{E V}_{B}^{*}\right.$, $\left.\overline{E V}_{W}^{*}, R^{*}(x)\right)$ such that:

$$
\begin{gathered}
\Psi_{B}\left(N_{W}, \overline{E V}_{B}^{*}\right)=\Psi_{W}\left(N_{W}, \overline{E V}_{W}^{*}\right) \\
\Psi_{B}\left(N, \overline{E V}_{B}^{*}\right)=R_{A}=0 \\
R^{*}(x)=\max \left\{\Psi_{B}\left(x, \overline{E V_{B}^{*}}\right), \Psi_{W}\left(x, \overline{E V}_{W}^{*}\right), 0\right\} \quad \text { at each } x \in(0, N]
\end{gathered}
$$

Equations (36) and (37) reflect the equilibrium conditions in the land market. Equation (36) says that, in the land market, at the frontier $N_{W}$, the bid rent offered by white workers is equal to the bid rent offered by black workers. Equation (37), in turn, says that the bid rent of black workers at the city-fringe must be equal to the agricultural land, which is normalized to zero. Finally, as in the previous section, equation (38) defines the equilibrium land rent as the upper envelope of the equilibrium bid rent curves of all workers and the agricultural rent line. Observe that housing discrimination does not affect the housing prices

\footnotetext{
${ }^{35}$ We could introduce differences in these variables but this would just reinforce our results.
} 
paid by blacks because their bid rents are flatter than that of whites, who would have paid lower rents had they live at the periphery.

By solving the first two equations, we obtain:

$$
\begin{aligned}
& \overline{E V}_{B}^{*}=e_{B}^{*}(N)[y-b-(1-s) \tau N]+b-s \tau N \\
& \overline{E V}_{W}^{*}=\left[e_{W}^{*}\left(N_{W}\right)-e_{B}^{*}\left(N_{W}\right)\right]\left[y-b-(1-s) \tau N_{W}\right] \\
& +e_{B}^{*}(N)[y-b-(1-s) \tau N]+b-s \tau N
\end{aligned}
$$

Finally, by plugging these values into the bid rent function, we get:

$$
R^{*}(x)=\left\{\begin{array}{cl}
e_{W}^{*}(x)[y-b-(1-s) \tau x]-e_{B}^{*}(N)[y-b-(1-s) \tau N] & \text { for } 0 \leq x \leq N_{W} \\
-\left[e_{W}^{*}\left(N_{W}\right)-e_{B}^{*}\left(N_{W}\right)\right]\left[y-b-(1-s) \tau N_{W}\right]+s \tau(N-x) & \\
e_{B}^{*}(x)[y-b-(1-s) \tau x]-e_{B}^{*}(N)[y-b-(1-s) \tau N]+s \tau(N-x) & \text { for } N_{W}<x \leq N
\end{array}\right.
$$

We have the following result:

Proposition 9 In the urban configuration described in Definition 3, whites spend more time with weak ties than blacks do, that is $\omega_{W}(x)>\omega_{B}(x), \forall x \in[0, N]$. This is, of course, also true on average, i.e. $\bar{\omega}_{W}>\bar{\omega}_{B}$, where

$$
\begin{aligned}
& \bar{\omega}_{W}=\frac{1}{N_{W}} \int_{0}^{N_{W}} \omega(x) d x \\
& \bar{\omega}_{B}=\frac{1}{N_{B}} \int_{N_{W}}^{N} \omega(x) d x
\end{aligned}
$$

This proposition is a consequence of housing discrimination and the fact that the time spent with weak ties is a decreasing function of the distance to jobs, i.e. $\omega_{j}^{\prime}(x)<0$. We know from Section 6.2 that $\omega_{j}^{\prime}(x)<0$ is a result of a choice since the marginal gain of interacting with weak ties is higher for workers residing closer to jobs than for those locating further away. In other words, this proposition links the physical and the social space since it says that separation in the physical space (here through housing discrimination) leads to separation in the social space, i.e. individuals living far away from jobs will mainly interact with their strong ties. In the context of black and white workers, this proposition shows that 
housing discrimination by separating black and white workers in the physical space does also separate them in the social space since black workers will find optimal not to commute to the $\mathrm{BD}$ to interact with weak ties and thus with whites.

There is some evidence that residents of high poverty neighborhoods rely more on strong ties, and on more geographically concentrated networks and thus less on weak ties. Elliot (1999) shows that less educated workers in high poverty neighborhoods are twice as likely to have found a job through neighbors (local contacts in the same group of city blocks) than in low poverty areas; this is consistent with evidence on the geographic concentration of social networks of poorer individuals, as reported in Fischer (1982) and Kadushin and Jones (1992). Moreover, jobholders in high poverty areas are more likely to have found jobs through strong rather than weak ties than in low poverty places ( $73 \%$ vs. $48 \%$ ).

Observe that, as explained in Section 3.2, the BD (Business District) is the unique employment center located at one end of a linear city. In a centralized city, it corresponds to the Central Business District, whereas in a completely decentralized city, it represents suburban employment. In the United States, black families tend to live in the city center while whites are more likely to reside in the suburbs. Even if there are jobs in the center, the jobs that low-skill black workers need are mostly located in the suburbs. This is the situation we are capturing here where black workers live far away to the $\mathrm{BD}$, i.e. the location where jobs are. For example, Raphael and Stoll (2002, Table 1) have categorized all Metropolitan Statistical Areas (MSAs) in the US according to the severity of their spatial mismatch, which measures the spatial imbalance between jobs and residential locations using an index of dissimilarity. In their measure, the dissimilarity index ranges from 0 to 100 , with higher values indicating a greater geographic mismatch between populations and jobs within a given metropolitan area. For instance, a dissimilarity index of 50 for blacks means that 50 percent of all blacks residing in the metropolitan area would have had to relocate to different neighborhoods within the metropolitan area in order to be spatially distributed in perfect proportion with jobs. Table 1 documents the spatial segregation of black workers in the US by giving the value of this dissimilarity index (denoted by $S M$ ) for both black and white families. It is easily seen that segregation/spatial mismatch of black families is very severe in the US, especially in big cities. ${ }^{36}$

\footnotetext{
$36 \%$ Pop: Percentage of (black or white) individuals in the population in the MSA or PMSA; SM: Measure of the Spatial Mismatch (for black or white) between people and jobs using the Raphael's and Stoll's dissimilarity index. \% Un: Percentage of (black or white) male unemployed in the MSA or PMSA.
} 
Table 1: Spatial mismatch in American MSAs in 2000

\begin{tabular}{|c|c|c|c|c|c|c|c|}
\hline & \multicolumn{3}{|c|}{ Blacks } & \multicolumn{3}{c|}{ Whites } & \\
\hline & $\%$ Pop & SM & $\%$ Un & $\%$ Pop & SM & $\%$ Un & Population \\
\hline Atlanta, GA MSA & 29 & 54 & 8.98 & 63 & 40 & 3.09 & $4,112,198$ \\
\hline Baltimore, MD, PMSA & 27 & 52 & 11.69 & 67 & 37 & 3.05 & $2,552,994$ \\
\hline Chicago, IL PMSA & 19 & 69 & 17.27 & 66 & 34 & 4.18 & $8,272,768$ \\
\hline Cleveland-Lorain-Elyria, OH, PMSA & 19 & 62 & 14.09 & 77 & 31 & 4.17 & $2,250,871$ \\
\hline Detroit, MI, PMSA & 23 & 71 & 14.89 & 71 & 36 & 4.27 & $4,441,551$ \\
\hline Houston, TX, PMSA & 17 & 57 & 10.85 & 61 & 40 & 4.46 & $4,117,646$ \\
\hline Los Angeles-Long Beach, CA, PMSA & 10 & 62 & 15.57 & 49 & 37 & 6.64 & $9,519,338$ \\
\hline Miami, FL, PMSA & 20 & 65 & 13.44 & 70 & 36 & 6.23 & $2,253,362$ \\
\hline New York, NY, PMSA & 25 & 70 & 14.63 & 49 & 44 & 5.61 & $9,314,235$ \\
\hline Newark, NJ, PMSA & 22 & 65 & 13.90 & 66 & 34 & 3.96 & $2,032,989$ \\
\hline Oakland, CA, PMSA & 13 & 55 & 12.08 & 55 & 37 & 3.95 & $2,392,557$ \\
\hline Philadelphia, PA-NJ, PMSA & 20 & 64 & 13.93 & 72 & 34 & 4.47 & $5,100,931$ \\
\hline Saint Louis, MO-IL, MSA & 18 & 63 & 14.21 & 78 & 38 & 4.11 & $2,603,607$ \\
\hline Washington, DC-MD-VA-WV, PMSA & 26 & 56 & 8.64 & 60 & 42 & 2.63 & $4,923,153$ \\
\hline
\end{tabular}

Source: Raphael and Stoll (2002) and Census (2000), calculations from the author.

\subsection{Labor-market equilibrium}

We would like now to analyze the consequence of the "double" separation of black workers (Proposition 9) on their labor-market outcomes. Let us write the flows of dyads between states for black and white workers. For a worker of type $j=B, W$, they are given by:

$$
\left\{\begin{array}{l}
\dot{d_{2 j}}(t)=h_{j}(t) d_{1 j}(t)-2 \delta d_{2 j}(t) \\
\dot{d_{1 j}}(t)=2 g(x, t) d_{0 j}(t)-[\delta+h(x, t)] d_{1 j}(t)+2 \delta d_{2 j}(t) \\
\dot{d_{0 j}}(t)=\delta d_{1 j}(t)-2 g(x, t) d_{0 j}(t)
\end{array}\right.
$$

where $h_{j}(t) \equiv\left(1-\bar{\omega}_{j}\right) \lambda+\bar{\omega}_{j}\left[\frac{N_{B}}{N} e_{B}(t)+\frac{N_{W}}{N} e_{W}(t)\right] \lambda$ and $g_{j}(t) \equiv \bar{\omega}_{j}\left[\frac{N_{B}}{N} e_{B}(t)+\frac{N_{W}}{N} e_{W}(t)\right] \lambda$, and with $\bar{\omega}_{B}<\bar{\omega}_{W}$ (Proposition 9). Indeed, when calculating the aggregate flows in the labor market for each type of workers, we use the average time workers of each type spend with their weak ties, that is $\bar{\omega}_{j}$, which are defined by (39) and (40). Let us explain the first equation since the interpretation of the other equations is similar. The variation of dyads composed of two employed workers of type $j\left(\dot{d}_{2 j}(t)\right)$ is equal to the number of $d_{1 j}$-dyads in which the unemployed worker of type $j$ has found a job through either his strong tie of 
type $j$ with probability $\left(1-\bar{\omega}_{j}\right) \lambda$ or his weak tie with probability $\bar{\omega}_{j}\left[\frac{N_{B}}{N} e_{B}(t)+\frac{N_{W}}{N} e_{W}(t)\right] \lambda$ minus the number of $d_{2 j}$-dyads in which one of the two employed workers has lost his job. It is important to understand why the probability of finding a job through a weak tie is $\bar{\omega}_{j}\left[\frac{N_{B}}{N} e_{B}(t)+\frac{N_{W}}{N} e_{W}(t)\right] \lambda$ for workers of type $j$. When a person of type $j=B, W$ who spends on average $\bar{\omega}_{j}$ of his time with weak ties goes to the $\mathrm{BD}$, he can meet a weak tie who is either an employed black worker who is aware of a job opportunity with probability $\frac{N_{B}}{N} e_{B}(t) \lambda$ or an employed white worker who is aware of a job opportunity with probability $\frac{N_{W}}{N} e_{W}(t) \lambda$. In other words, there is no meeting bias with weak ties but there is a strong meeting bias with strong ties (since a person of type $j$ only meets his strong tie belonging to the same race $j$ all his life). This is to capture the idea that people are born with a type $j$ and interacts with strong ties of the same type $j$ because they are either members of the family or very close friends met during the childhood. On the contrary, individuals meet weak ties randomly by going to bars, doing sport activities or shopping in the BD. In that case, they meet randomly other people of either race. We could have assumed, like for example in Currarini et al (2009), a meeting bias (the probability to meet an employed weak tie who is informed for a black individual would be $\bar{\omega}_{j}\left[\frac{N_{B}}{N} e_{B}(t)+m \frac{N_{W}}{N} e_{W}(t)\right] \lambda$, where $0<m<1$ and likewise for whites) but this would complicate the analysis without changing our main results.

Taking into account (35), the system (41) reduces to a two-dimensional dynamic system in $d_{2}(t)$ and $d_{1}(t)$ given by:

$$
\left\{\begin{array}{l}
\dot{d}_{2 j}(t)=h_{j}(t) d_{1 j}(t)-2 \delta d_{2 j}(t) \\
\dot{d}_{1 j}(t)=2 g_{j}(t)\left[N_{j} / 2-d_{2 j}(t)-d_{1 j}(t)\right]-\left[\delta+h_{j}(t)\right] d_{1 j}(t)+2 \delta d_{2 j}(t)
\end{array}\right.
$$

where

$$
N_{j} e_{j}(t)=2 d_{2 j}(t)+d_{1 j}(t)
$$

In a steady-state $\left(d_{2 j}^{*}, d_{1 j}^{*}, d_{0 j}^{*}\right)$, each of the net flows in (41) is equal to zero. Setting these net flows equal to zero leads to the following relationships for workers of type $j$ :

$$
\begin{gathered}
d_{2 j}^{*}=\frac{\left(1-\bar{\omega}_{j}\right) \lambda+\bar{\omega}_{j} \lambda\left(\frac{N_{B}}{N} e_{B}^{*}+\frac{N_{W}}{N} e_{W}^{*}\right)}{2 \delta} d_{1 j}^{*} \\
d_{1 j}^{*}=\frac{2 \bar{\omega}_{j} \lambda\left(\frac{N_{B}}{N} e_{B}^{*}+\frac{N_{W}}{N} e_{W}^{*}\right)}{\delta} d_{0 j}^{*} \\
d_{0 j}^{*}=\frac{N_{j}}{2}-d_{2 j}^{*}-d_{1 j}^{*}
\end{gathered}
$$


where

$$
\begin{gathered}
N_{j} e_{j}^{*}=2 d_{2 j}^{*}+d_{1 j}^{*} \\
u_{j}^{*}=1-e_{j}^{*}
\end{gathered}
$$

The model is much more complicated now because $e_{B}^{*}$ and $e_{W}^{*}$ enter both in each dyad of each type $j$ of worker and, as a result, we cannot analyze the steady-state equilibrium separately for black and white workers. We have the following result:

\section{Proposition 10}

(i) There always exists a steady-state equilibrium $\mathcal{U}$ where all individuals are unemployed and only $d_{0 j}-$ dyads exist, that is $d_{2 j}^{*}=d_{1 j}^{*}=e_{j}^{*}=0, d_{0 j}^{*}=N_{j} / 2$ and $u_{j}^{*}=1$ for $j=B, W$.

(ii) All the other steady-state equilibria are interior, that is $0<e_{B}^{*}<1$ and $0<e_{W}^{*}<1$. These equilibria are characterized by:

$$
\frac{N_{B} e_{B}^{*}+N_{W} e_{W}^{*}}{N}=\frac{N \delta^{2}-2 \lambda^{2} \bar{\omega}_{B} d_{0 B}^{*}\left(1-\bar{\omega}_{B}\right)-2 \lambda^{2} \bar{\omega}_{W} d_{0 W}^{*}\left(1-\bar{\omega}_{W}\right)}{2 \lambda\left[\bar{\omega}_{B} d_{0 B}^{*}\left(\lambda \bar{\omega}_{B}+\delta\right)+\bar{\omega}_{W} d_{0 W}^{*}\left(\lambda \bar{\omega}_{W}+\delta\right)\right]}
$$

Furthermore, if the separation in the physical space for blacks is sufficiently high (meaning that $\left.\bar{\omega}_{W}>>\bar{\omega}_{B}\right)$, i.e.

$$
\frac{\bar{\omega}_{W}}{\bar{\omega}_{B}}>\frac{N_{W}}{N_{B}} \frac{d_{0 B}^{*}}{d_{0 W}^{*}}
$$

then the employment rate (unemployment rate) of black workers is lower (higher) than that of whites, i.e. $e_{B}^{*}<e_{W}^{*}$ and $u_{B}^{*}>u_{W}^{*}$.

This proposition formally proves the intuition developed earlier. If black workers are sufficiently separated in the physical space, then they will mainly interact with their black strong ties and will therefore have very little interaction with weak ties, especially whites. Weak ties are an important source of job information and when black individuals miss it, they end up having a higher unemployment rate than whites. This is a vicious circle since blacks experience a higher unemployment rate and mostly rely on other black workers who also experience a high unemployment rate, etc. Since jobs are mainly found through social networks via employed friends, black individuals are stuck in their location with no job. In particular, those residing far away from jobs, will mainly rely on their weak ties. As a result, 
when they found themselves in a $d_{0}$-dyad, they have nearly no chance of leaving it since the only way out is to meet an employed weak tie. As underscored by Granovetter (1973, $1974,1983)$, in a close network where everyone knows each other, information is shared and so potential sources of information are quickly shaken down so that the network quickly becomes redundant in terms of access to new information. In contrast Granovetter stresses the strength of weak ties involving a secondary ring of acquaintances who have contacts with networks outside ego's network and therefore offer new sources of information on job opportunities. To summarize, when the time spent with weak ties is low, the social cohesion between employed and unemployed workers is also low and thus they are not in close contact with each other. Therefore, little interaction with weak ties induces more transitions from employment to unemployment and thus the unemployment rate increases.

Fernandez and Fernandez-Mateo (2006) elaborate the various network mechanisms by which minorities can be isolated from good job opportunities. Using unique data from one employer, they examine multiple steps in the chain of network referral processes originating from employees to the applicants for entry-level jobs at this employer. They study access to a set of desirable jobs that are within reach of candidates with modest levels of education and skills. By examining the minority versus non-minority representation in the pool of people who could potentially originate word-of-mouth networks to this employer, they find relatively large percentages of Asian Americans and Hispanics, but small percentages of African Americans, available to refer others in this setting.

It is important to observe that the results of Proposition 10, especially the fact that $e_{B}^{*}<e_{W}^{*}$ and $u_{B}^{*}>u_{W}^{*}$ are obtained when blacks and whites are assumed to be totally identical (in terms of wage, commuting costs, job-destruction rate, job-information rate, etc.). In a world where job information flows through word-of-mouth communication, the differences in employment and unemployment rates between blacks and whites are only caused by the separation in the physical space due to housing discrimination. The analysis thus generates a link between unemployment and a seemingly unrelated phenomenon: racial discrimination in the housing market. Because the model is difficult to solve analytically, we would like now to run some numerical simulations highlighting the impact of segregation on labor-market outcomes of black workers.

\subsection{Numerical simulations}

Take our model and interpret the time period as one quarter of a year. The job destruction rate is equal to $\delta=0.1$, that is, workers keep on average their job for 2 years and 6 months. Remember that these are unskilled jobs. The job information rate is equal to $\lambda=0.8$, which 
means that an employed worker is aware about a job every 3 months (and 20 days). We fix the total population to $N=1,000$ with 20 percent blacks and 80 percent whites, i.e. $N_{B}=200$ and $N_{W}=800$. Concerning social interactions, we assume the following linear function:

$$
\omega(x)=\frac{N-x}{N}
$$

which is decreasing in $x$, with $\omega(0)=1$ and $\omega(N)=0$. This implies that, for whites, the average time spent with weak time is (see (39)):

$$
\bar{\omega}_{W}=\frac{1}{N_{W}} \int_{0}^{N_{W}}\left[\frac{N-x}{N}\right] d x=\frac{N+N_{B}}{2 N}
$$

while, for blacks, we have (see (40)):

$$
\bar{\omega}_{B}=\frac{1}{N_{B}} \int_{N_{W}}^{N}\left[\frac{N-x}{N}\right] d x=\frac{N_{B}}{2 N}
$$

Using (42) to (46), for each $j=B, W$, we obtain:

$$
\begin{gathered}
d_{2 j}^{*}=\frac{\lambda^{2} \bar{\omega}_{j}\left[1-\bar{\omega}_{j}+\bar{\omega}_{j}\left(\frac{N_{B}}{N} e_{B}^{*}+\frac{N_{W}}{N} e_{W}^{*}\right)\right]\left(\frac{N_{B}}{N} e_{B}^{*}+\frac{N_{W}}{N} e_{W}^{*}\right)}{\delta^{2}} d_{0 j}^{*} \\
d_{1 j}^{*}=\frac{2 \bar{\omega}_{j} \lambda\left(\frac{N_{B}}{N} e_{B}^{*}+\frac{N_{W}}{N} e_{W}^{*}\right)}{\delta} d_{0 j}^{*} \\
d_{0 j}^{*}=\frac{N_{j} \delta^{2}}{2 \lambda \bar{\omega}_{j}\left(\frac{N_{B}}{N} e_{B}^{*}+\frac{N_{W}}{N} e_{W}^{*}\right)\left[\lambda \bar{\omega}_{j}\left(\frac{N_{B}}{N} e_{B}^{*}+\frac{N_{W}}{N} e_{W}^{*}-1\right)+\lambda+2 \delta\right]+2 \delta^{2}} \\
e_{j}^{*}=\frac{2 d_{2 j}^{*}+d_{1 j}^{*}}{N_{j}} \\
u_{j}^{*}=1-e_{j}^{*}
\end{gathered}
$$

where $\frac{N_{B}}{N} e_{B}^{*}+\frac{N_{W}}{N} e_{W}^{*}$ is given by $(47)$.

The results of the simulations are displayed in Table 2. As can be seen in this table, the only (ex ante) difference between blacks and whites is their location in the geographical space. Since housing consumption has been normalized to 1 , the city size is equal to $N=1,000$. The area where whites live is between $x=0$ and $x=800$ and the area where blacks reside is between $x=800$ and $x=1,000$. As a result, the average time spent with weak ties is only 10 percent for black workers while it is 60 percent for white workers. At the steady-state 
equilibrium, this initial difference translates into large differences in labor-market outcomes between these two populations. First, the unemployment rate of black workers is nearly twice as much as that of white workers (22 versus 13 percent). This can be explained by the fact that black families spend more than 13 percent of their time in a $d_{0}$ dyad $^{37}$ while whites spend only 2.6 percent of their time in this type of dyad. Interestingly, because $\lambda$ is relatively high (employed workers of either race hears of a job opportunity every 3 months), black workers do also spend a lot of time in a $d_{2}$ dyad (69 percent) where both strong ties are employed.

Table 2: Steady-state equilibrium

\begin{tabular}{|c|c|c|}
\hline & Black workers & White workers \\
\hline $\bar{\omega}_{j}^{*}$ & 0.1 & 0.6 \\
\hline$u_{j}^{*}$ & 0.22 & 0.13 \\
\hline$d_{0 j}^{*}$ & 13.20 & 10.59 \\
\hline $2 d_{0 j}^{*} / N_{j}$ & 0.132 & 0.026 \\
\hline$d_{1 j}^{*}$ & 17.59 & 84.67 \\
\hline $2 d_{1 j}^{*} / N_{j}$ & 0.176 & 0.212 \\
\hline$d_{2 j}^{*}$ & 69.21 & 304.75 \\
\hline $2 d_{2 j}^{*} / N_{j}$ & 0.692 & 0.762 \\
\hline
\end{tabular}

This first result highlights the large different outcomes between blacks and whites mainly due to the separation of the former in the physical space. We would like now to see more closely how the increase in segregation affects these outcomes. For that, we vary $N_{W}$, which measures the size of the area where whites live, and analyze its impact on the labor market. Notice that by increasing $N_{W}$ and by keeping $N$ fixed, we reduce the size of the black population but, more importantly, we increase $\bar{\omega}_{W}^{*}$ and reduce $\bar{\omega}_{B}^{*}$. Figure 3 displays the results for the unemployment rates. In this figure and all the figures below, the solid line corresponds to outcomes of black workers while the dashed line to that of white workers.

\footnotetext{
${ }^{37}$ For the interpretation of the results, it is better to use $2 d_{0 j}^{*} / N_{j}$ than $d_{0 j}^{*}$ since the former is normalized and gives the time spent in a $d_{0}$ dyad. The same applies for $d_{1 j}^{*}$ and $d_{2 j}^{*}$.
} 


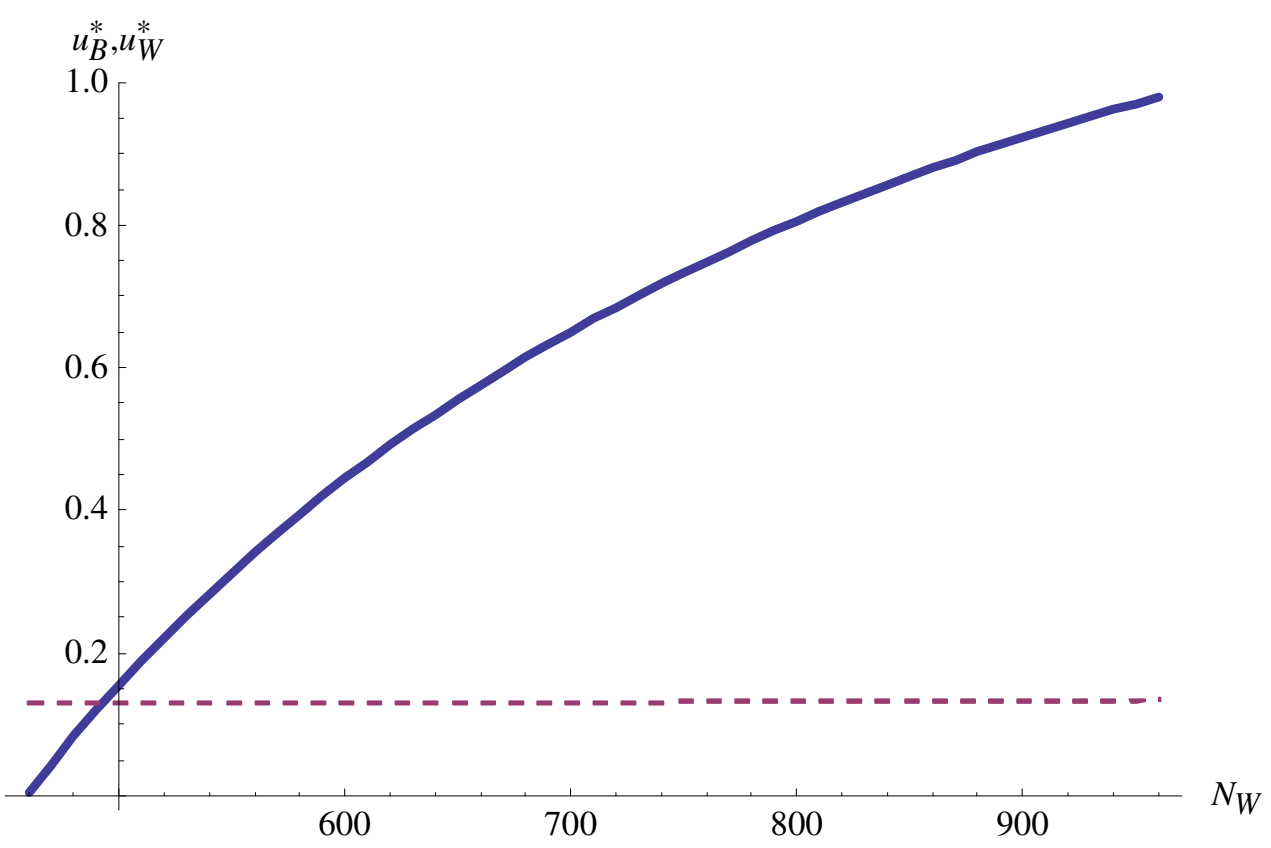

Figure 3: Effect of segregation on unemployment rates.

It can be seen that increasing segregation is mainly detrimental to blacks, which experience an increase in their unemployment rate from 15.5 percent (when there are as many blacks as whites in the population, i.e. $N_{B}=N_{W}=500$ and $\left.\bar{\omega}_{B}=0.25, \bar{\omega}_{W}=0.75\right)$ to more than 90 percent when there is a majority of whites (i.e. $N_{B}=100$ and $N_{W}=900$ and $\left.\bar{\omega}_{B}=0.05, \bar{\omega}_{W}=0.55\right)$. Observe that, by increasing $N_{W}$ whites also suffer, since their $\bar{\omega}_{W}$ decreases but by only 26.67 percent while blacks experience a reduction of 80 percent in their average time they spend with weak ties. Interestingly, for whites, the unemployment rate is nearly unaffected by the increase in segregation since it increases from 13 percent to 13.35 percent. Let us understand better this sharp increase in the black unemployment rate by looking at the changes in the different dyads when $N_{W}$ increases. Figures 4,5 , and 6 show these results for the $d_{0}$-dyads, $d_{1}$-dyads and $d_{2}$-dyads, respectively. 


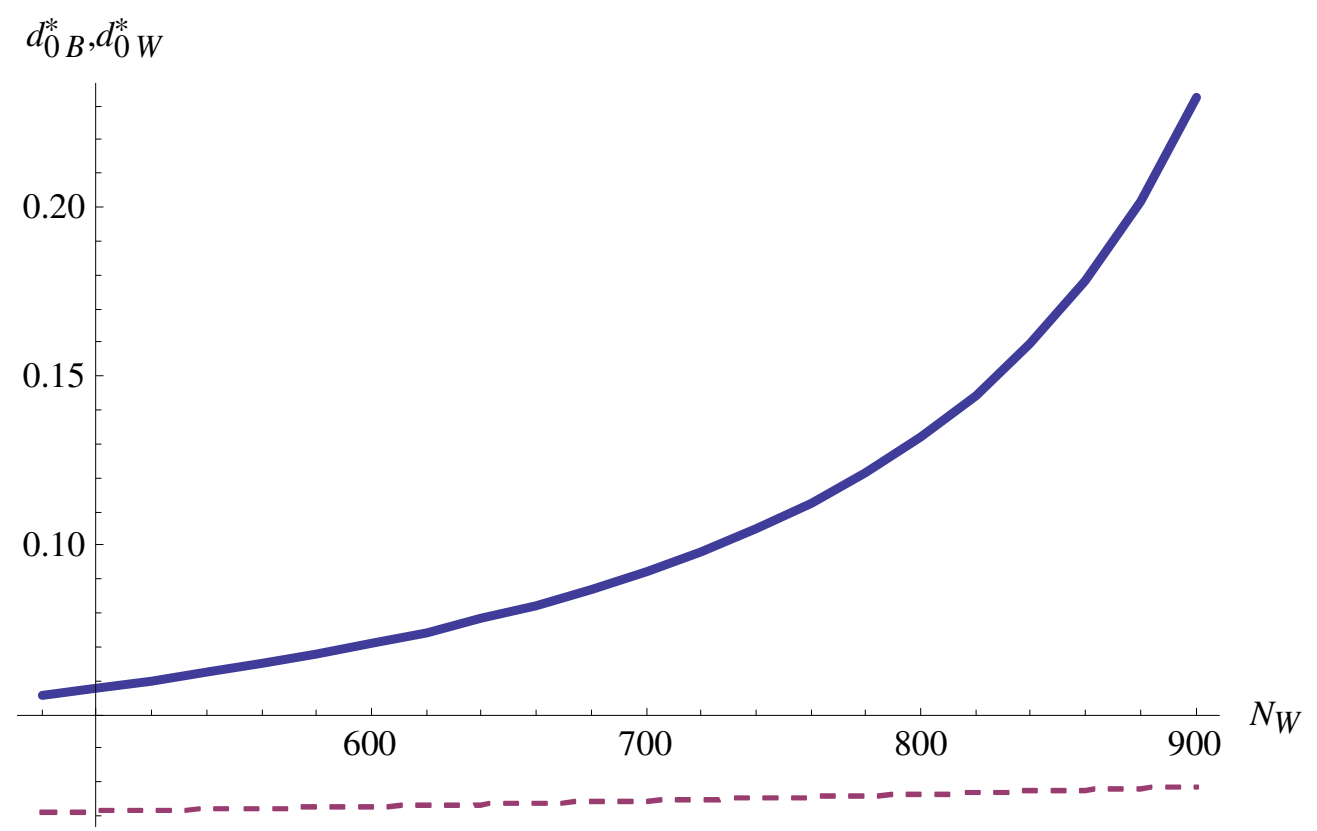

Figure 4: Effect of segregation on the time spent in $d_{0}$ dyads.

It is striking to see that one of the main effects of increasing segregation is that blacks spend much more time in $d_{0}$-dyads, meaning that both strong ties are unemployed and can only find a job through their weak ties. In Figure 4, it can be seen that black workers spend 5.8 percent of their time in $d_{0}$-dyads when $N_{B}=N_{W}=500$ while this number increases to more than 23 percent when $N_{B}=100$ and $N_{W}=900$. In the latter, this is a very difficult situation since, on average, black workers meet weak ties only 5 percent of their time (i.e. $\left.\bar{\omega}_{B}=0.05\right)$. This is why the unemployment rate is as high as 90 percent since there is extremely little chance for them of escaping unemployment. Indeed, in a $d_{0}$ dyad, both strong ties are unemployed and these workers only meet weak ties 5 percent of their time. This highlights the vicious circle we put forward in the Introduction. If black workers do not have access to weak ties (especially whites), in particular because they are segregated and separated from business centers, then their main source of information about jobs will be provided by their strong ties. But if the latter are themselves unemployed, the chance of escaping unemployment will be very low. 


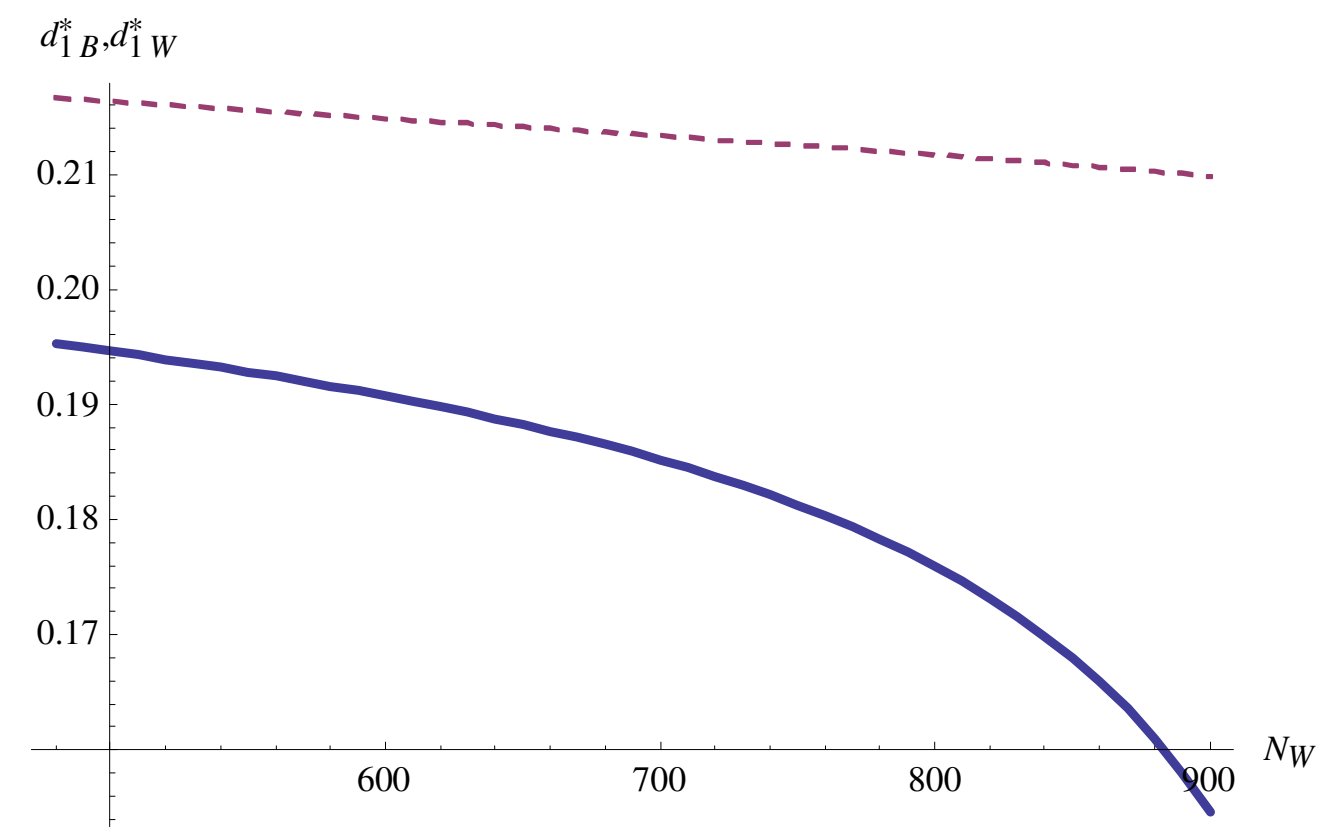

Figure 5: Effect of segregation on the time spent in $d_{1}$ dyads.

Figures 5 and 6 analyze the impact of segregation on the time spent in $d_{1}$-dyads and $d_{2}$-dyads, respectively. It can be seen again that blacks are mostly affected by the increase in segregation while whites are not. In particular, the time spent in $d_{1}$ and $d_{2}$-dyads, where either one or two persons in the dyad is employed, sharply decreases with the increase of segregation. 


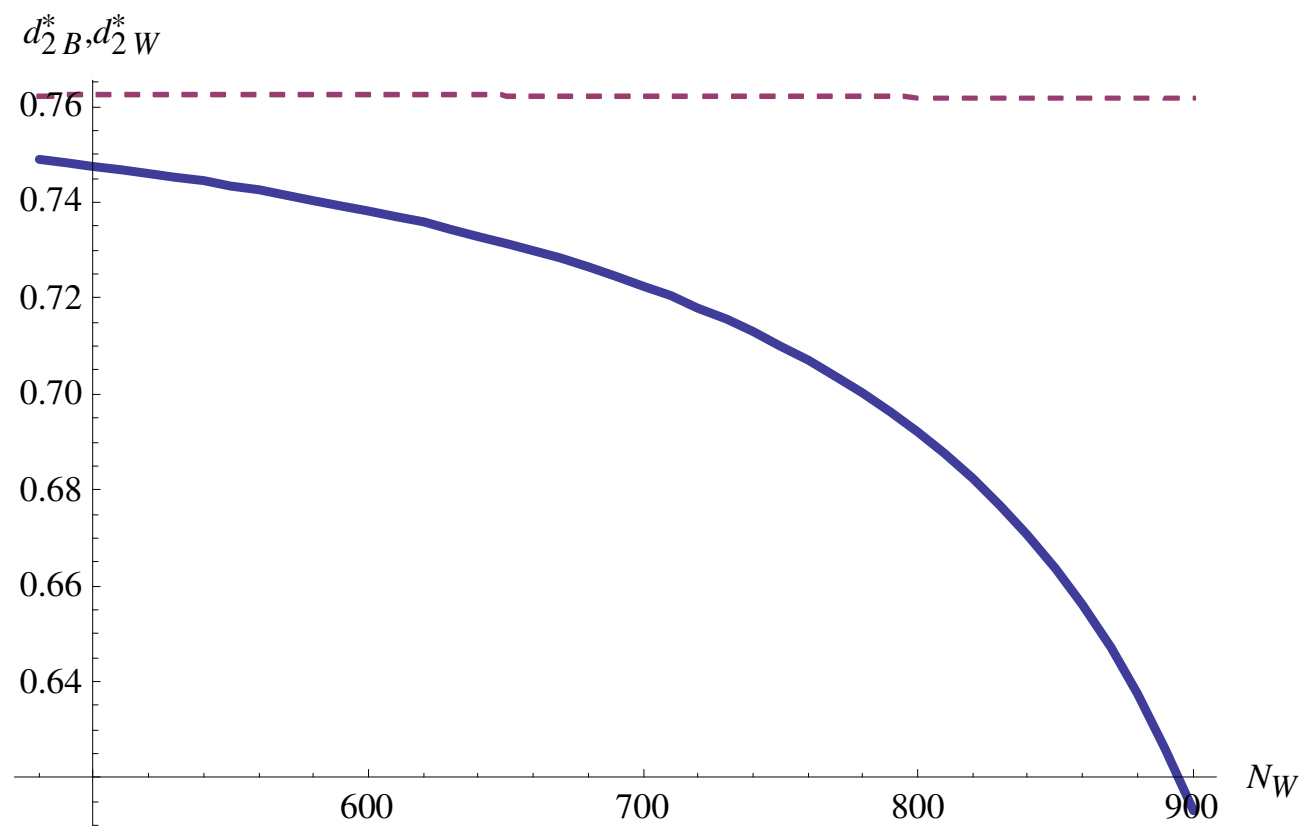

Figure 6: Effect of segregation on the time spent in $d_{2}$ dyads.

We have also performed other numerical simulations to see how robust our results are. ${ }^{38}$ For example, instead of taking the decreasing and linear function (49), we have also used the following decreasing but convex function of social interactions: $\omega(x)=1 /(1+x)$, which disadvantages even more distant workers. In that case, all results remain qualitatively unchanged. We have also run other simulations with different job-destruction rates $\delta$ and job-information rates $\lambda$ and still find the same qualitative results.

To sum up, our model highlights the fact that minority workers, especially blacks, are both cut off from employment opportunities (because of distance to jobs) and are embedded in the "wrong" network, that is, they tend to overuse networks (i.e. strong ties) that lead to no job at all. For example, Kasinitz and Rosenberg (1996) argue that poor, black residents of the Red Hook section of Brooklyn are cut off from good jobs on the waterfront. Since people tend to be hired into these jobs only through connections to union members who already work there, and since few African Americans are currently employed on the waterfront, they argue that African Americans are missing the connection to these jobs. Similarly, Newman (1995, 1999) in her studies of Harlem's low-wage service workers argues that black youth also rely on networks in their job finding, but that these networks tend to lead them to low-paying jobs.

\footnotetext{
${ }^{38}$ These simulations are available upon request.
} 


\section{Discussion and policy implications}

Because of the results of the previous section, our model can provide a mechanism explaining why black workers, who tend to live far away from jobs in the United States, experience high unemployment rates. Our explanation of the spatial mismatch is that distant (black) workers live in neighborhoods based on closed networks, which are limited in getting information about possible jobs. Because of the lack of good public transportation in the US, it is costly (both in terms of time and money) to commute to business centers to meet other types of people who can provide other source of information about jobs. If distant (black) workers mainly rely on their strong ties and if the latter are unemployed, there is then little chance to escape unemployment and to find a job. ${ }^{39}$

Our result is also related to that of Calvó-Armengol and Jackson (2004). Contrary to the present model where only a very specific network structure (i.e. the dyad) is assumed, they explicitly model a social network (which can have any possible structure) where information flows between individuals having a link with each other. They show that an equilibrium with a clustering of workers with the same status is likely to emerge since, in the long run (i.e. steady state), employed workers tend to be friends with employed workers. Apart from the fact that there is no urban space, the main difference with our approach is that individuals exchange job information only with their strong ties (as defined by their direct friends). In their model, weak ties (as defined by friends of friends) will indirectly help individuals because, by providing job information to their strong ties, they help them to become employed. The two approaches are complementary. In Calvó-Armengol and Jackson (2004), if because of some initial condition some black workers are unemployed, then in steady-state they will still be unemployed because both their strong and weak ties will also be unemployed. In our framework, it is segregation and distance to a business center that make black workers only interacting with strong ties, who are themselves likely to be unemployed.

Our model is mainly based on the fact that blacks are segregated in the physical space, residing far away from jobs (see, for example, Table 1 in Section 7.2 for evidence) and that job information exchange is localized (either you talk to your strong ties who live in the same neighborhood ${ }^{40}$ or you meet randomly people in the job-activity center). We have

\footnotetext{
${ }^{39}$ Even if this is beyond the scope of this paper, our model could also explain the emergence of a "black culture" in areas far away from jobs since distance to jobs induces the black population to rely mostly on strong ties.

${ }^{40}$ See e.g. Wellman (1996) who finds that $42 \%$ of yearly contacts in individual networks took place with neighbors that lived less than one mile away. See also Guest and Lee (1983), Otani (1999), Conley and Topa
} 
shown that, even if black and white workers are totally identical, black segregation will create stark differences in unemployment rates between blacks and whites. Interestingly, using confidential longitudinal data from the 1979 National Longitudinal Survey of Youth (NLSY), Weinberg et al. (2004) investigate the presence of social interaction effects at the neighborhood level on labor market activity. They also examine the possibility that any correlation in outcomes across neighborhood residents may be explained by the "spatial mismatch" hypothesis. They find that a one standard deviation increase in access to jobs (the spatial mismatch hypothesis) is associated with a $3.6 \%$ increase in annual hours worked. Similarly, Card and Rothstein (2007) find that, holding constant family background and other factors, a shift from a fully segregated to a completely integrated city closes about one-quarter of the raw black-white gap in SAT scores.

Our analysis offers interesting policy implications. We have shown that the neighborhood and distance to jobs are crucial in understanding labor-market outcomes of ethnic minorities. In that case, neighborhood regeneration policies are the right tool to use. Such policies have been implemented in the US and in Europe through the enterprise zone programs (Papke, 1994; Boarnet and Bogart, 1996; Mauer and Ott, 1999; Bondonio and Engberg, 2000; Bondonio and Greenbaum, 2007) and the empowerment zone programs (Busso and Kline, 2008). For example, the enterprise zone policy consists in designating a specific urban (or rural) area, which is depressed, and targeting it for economic development through government-provided subsidies to labor and capital. The aim of the empowerment zone program is to revitalize distressed urban communities and it represents a nexus between social welfare policy and economic development efforts. By implementing these types of policies, one brings jobs to people and thus facilitates the flows of job information in depressed neighborhoods.

Policies that promote social integration and thus increase the interracial interactions between weak ties would also have positive effects on the labor-market outcomes of minority workers. Such policies, like the Moving to Opportunity (MTO) programs (Katz et al., 2001; Rosenbaum and Harris, 2001; Kling et al., 2005), have been implemented in the United States. By giving housing assistance to low-income families, the MTO programs help them relocate to better and richer neighborhoods. ${ }^{41}$

(2002) and Bayer et al. (2008).

${ }^{41}$ See also Beaman (2011) and Edin et al. (2003) who both exploit natural experiments, consisting of refugee resettlement programs in the U.S. and Sweden, respectively, to try to disentangle social network referral effects from sorting or correlation in unobservable attributes. Beaman (2011) finds that a one standard deviation increase in the number of network members in a given year lowers the employment probability of someone arriving one year later by 4.9 percentage points. Edin et al. (2003) find similar 
In light of our results, our model predicts that, relative to the 'control' group, displaced workers (from low- to high-rental-housing areas) should improve their social network and therefore their labor outcomes. If labor market participation is a good 'proxy' for labor outcomes, then the findings of Rosenbaum and Harris (2001) confirm some of the predictions of our model. Indeed, using the survey data from the MTO program in Chicago, the findings of these authors, based on interviews an average of 18 months after families moved from public housing to higher rental housing areas, show an increase in labor force participation and employment. More precisely, Rosenbaum and Harris (2001) show that: "After moving to their new neighborhoods, the Section 8 respondents were far more likely to be actively participating in the labor force (i.e. working or looking for a job), while for MTO respondents, a statistically significant increase is evident only for employment per se."

Another way of reducing the unemployment rate of minorities in the context of our model is to observe that institutional connections can be engineered to create connections between job seekers and employers in ways that parallel social network processes. For example, scholars like Granovetter (1979) and Wilson (1996) have called for poverty reduction programs to "create connections" between employers and poor and disadvantaged job seekers. While labor market intermediaries of all types aim to place workers with employers, especially with respect to poor populations, there is some disagreement about how these linkages work. Although strengthening connections being poor job seekers and employers is often seen as desirable, past research has questioned whether labor market intermediaries actually perform this function for those most in need. Recently, Autor and Houseman (2010) have argued that in the low wage sector temporary services can help workers in the short term, but is not helpful in the longer-term because tempory employment weakens workers' search efforts for direct hire jobs. On the employer's side, a number of studies have shown that employers often stigmatize low wage workers who are sent to them by public and private labor market intermediaries (e.g., Laufer and Winship, 2004). In general, employers are concerned that since intermediaries targeting poor populations specialize in hard-to-employ populations, candidates referred by these organizations will be adversely selected, constituting the labor market "left-overs" who could not find a job through other means (Autor, 2009; Burtless, 1985; Van Ours, 1994). While low-wage employers generally stigmatize job-seekers sent to them from labor market intermediary organizations, Fernandez (2010) shows how it is that such biases can be overcome. To the degree that intermediary organizations can help the firm address its recruitment problems, "created connections" can serve as functional substitutes for social network processes in matching people to jobs. Actors will choose to work with positive results. 
brokers to the extent that brokers provide goods or services that are of greater value than those available through alternative means.

To conclude, we believe that weak ties generate 'bridging' social capital. Bridging social capital refers to ties across networks that may make the resources exist in one network accessible to a member of another. These social relationships enable members to 'get ahead'. These are needed to extend beyond family to connect to a broader range of resources and opportunities that exist in networks to which they are otherwise not connected. If black workers do not have access to weak ties (especially whites), in particular because they are segregated and separated from business centers, then their main source of information about jobs will be provided by their strong ties. But if the latter are themselves unemployed, the chance of escaping unemployment will be very low.

\section{References}

[1] Akerlof, G. (1997), "Social distance and social decisions," Econometrica 65, 1005-1027.

[2] Alesina, A. and E. La Ferrara (2002), "Who trust others?" Journal of Public Economics 85, 207-234.

[3] Autor, D.H. and S.N. Houseman (2010), "Do temporary-help jobs improve labor market outcomes for low-skilled workers? Evidence from "Work First"," American Economic Journal: Applied Economics 2, 96-128.

[4] Autor, D.H. (2009), "The economics of labor market intermediation: An analytic framework," In: D. H. Autor (Ed.), Studies of Labor Market Intermediation, Chicago: University of Chicago Press, pp. 1-23.

[5] Ballester, C., Calvó-Armengol, A. and Y. Zenou (2006), "Who's who in networks. Wanted: the key player," Econometrica 74, 1403-1417.

[6] Barber, A. E., M. J. Wesson, Q. M. Roberson and M. S. Taylor (1999), "A tale of two job markets: Organizational size and its effects on hiring practices and job search behavior," Personnel Psychology 52, 841-867.

[7] Bartram, D., P. A. Lindley, L. Marshall and J. Foster (1995), "The recruitment and selection of young-people by small businesses," Journal of Occupational Organizational Psychology 68, 339-358. 
[8] Bayer, P., Ross, S.L. and G. Topa (2008), "Place of work and place of residence: Informal hiring networks and labor market outcomes," Journal of Political Economy $116,1150-1196$.

[9] Beaman, L.A. (2011), "Social networks and the dynamics of labor market outcomes: Evidence from refugees resettled in the U.S.," Review of Economic Studies, forthcoming.

[10] Bentolila, S., Michelacci, C. and J. Suarez (2010), "Social contacts and occupational choice," Economica 77, 20-45.

[11] Berthiaume, J. and W. Parsons (2006), "Referral bonuses: A popular way to bring in new talent." SHRM, http://moss07.shrm.org/hrdisciplines/compensation/Articles/Pages/CMS_016894.aspx.

[12] Bhat, C.R. (1997), "Work travel mode choice and number of non-work commute stops," Transportation Research Part B 31, 41-54.

[13] Bisin, A. and T. Verdier (2000), "Beyond the Melting Pot: Cultural Transmission, Marriage, and the Evolution of Ethnic and Religious Traits," Quarterly Journal of Economics 115, 955-988.

[14] Bisin, A. and T. Verdier (2001), "The Economics of Cultural Transmission and the Dynamics of Preferences," Journal of Economic Theory 97, 298-319.

[15] Boarnet, M.G. and W.T. Bogart (1996), "Enterprise zones and employment: Evidence from New Jersey," Journal of Urban Economics 40, 198-215.

[16] Bondonio, D. and J. Engberg (2000), "Enterprise zones and local employment: Evidence from the states' program," Regional Science and Urban Economics 30, 519-549.

[17] Bondonio, D. and R.T. Greenbaum (2007), "Do local tax incentives affect economic growth? What mean impact miss in the analysis of enterprise zone policies," Regional Science and Urban Economics 37, 121-136.

[18] Bridges, W.P. and W.J. Villemez (1986), "Informal hiring and income in the labor market," American Sociological Review 51, 574-582.

[19] Brueckner, J.K. and A.G. Largey (2008), "Social interaction and urban sprawl," Journal of Urban Economics 64, 18-34. 
[20] Burtless, G. (1985), "Are targeted wage subsidies harmful? Evidence for a wage voucher experiment," Industrial and Labor Relations Review 39, 105-114.

[21] Busso, M. and P. Kline (2008), "Do local economic development programs work? Evidence from the federal empowerment zone program," Yale University, Economics Department Working Paper No. 36.

[22] Calvó-Armengol, A. and M. Jackson (2004), "The effects of social networks on employment and inequality," American Economic Review 94, 426-454.

[23] Calvó-Armengol, A. and M. Jackson (2007), "Networks in labor markets: Wage and employment dynamics and inequality," Journal of Economic Theory 132, 27-46.

[24] Calvó-Armengol, A., Patacchini, E., and Y. Zenou (2009), "Peer Effects and Social Networks in Education," Review of Economic Studies 76, 1239-1267.

[25] Calvó-Armengol, A., Verdier, T. and Y. Zenou (2007), "Strong and weak ties in employment and crime," Journal of Public Economics 91, 203-233.

[26] Cappelli, P. and K. Chauvin (1991), "An interplant test of the efficiency wage hypothesis," Quarterly Journal of Economics 106, 769-787.

[27] Card, D. and J. Rothstein (2007), "Racial segregation and the black-white test score gap," Journal of Public Economics 91, 2158-2184.

[28] Conley, T.G. and G. Topa (2002), "Socio-economic distance and spatial patterns in unemployment," Journal of Applied Econometrics 17, 303-327.

[29] Coulson, E., Laing, D. and P. Wang (2001), "Spatial mismatch in search equilibrium," Journal of Labor Economics 19, 949-972.

[30] Costa, D.L. and M.E. Kahn (2003), "Civic engagement and community heterogeneity: An economist's perspective," Perspectives on Politics 1, 103-111.

[31] Currarini, S., Jackson, M.O., and P. Pin (2009), "An economic model of friendship: Homophily, minorities, and segregation," Econometrica 77, 1003-1045.

[32] Davis, S.J. and J.C. Haltiwanger (1992), "Gross job creation, gross job destruction, and employment reallocation," Quarterly Journal of Economics 107, 819-63. 
[33] Dawkins, C.J. (2006), "Are social networks the ties that bind families to neighborhoods?" Housing Studies 21, 867-881.

[34] Edin, P.-A., P. Fredriksson and O. Åslund (2003), "Ethnic enclaves and the economic success of immigrants. Evidence from a natural experiment," Quarterly Journal of Economics 118, 329-357.

[35] Elliot, J.R. (1999), "Social isolation and labor market insulation: Network and neighborhood effects on less-educated urban workers," Sociological Quarterly 40, 199-216.

[36] Fehr, E., Kirchsteiger, R. and A. Riedl (1996), "Involuntary unemployment and noncompensating wage differentials in an experimental labour market," Economic Journal 106, 106-121.

[37] Fehr, E. and L. Goette (2007), "Do workers work more if wages are high? Evidence from a randomized field experiment," American Economic Review 97, 298-317.

[38] Fernandez, R.M. and I. Fernandez-Mateo (2006), "Networks, race, and hiring," American Sociological Review 71, 42-71.

[39] Fernandez, R.M. (2010), "Creating connections for the disadvantaged: Networks and labor market intermediaries at the hiring interface," MIT Sloan School Working Paper No. $4778-10$.

[40] Fischer, C.S. (1982), To Dwell among Friends: Personal Networks in Town and City, Chicago: University of Chicago Press.

[41] Fu, S. (2005), "What has been capitalized into property values: Human capital, social capital, or cultural capital?" U.S. Census Bureau Center for Economic Studies, Working Paper No. 05-25.

[42] Fujita, M. (1989), Urban Economic Theory, Cambridge: Cambridge University Press.

[43] Fujita, M. and J.-F. Thisse (2002), Economics of Agglomeration. Cities, Industrial Location, and Regional Growth, Cambridge: Cambridge University Press.

[44] Glaeser, E.L. (2000), "The future of urban economics: Non-market interactions," Brookings-Wharton Papers on Urban Affairs 1, 101-150.

[45] Glaeser, E.L., Sacerdote, B., and J.A. Scheinkman (1996), "Crime and social interactions," Quarterly Journal of Economics 111, 508-548. 
[46] Glaeser, E.L., Laibson, D.I., Scheinkman, J.A., and C. L. Soutter (2000), "Measuring trust," Quarterly Journal of Economics 115, 811-846.

[47] Gobillon, L., Selod, H. and Y. Zenou (2007), "The mechanisms of spatial mismatch," Urban Studies 44, 2401-2427.

[48] Goldsmith, A.H., Veum, J.R. and W. Jr. Darity (2000), "Working hard for the money? Efficiency wages and worker effort," Journal of Economic Psychology 21, 351-385.

[49] Goyal, S. (2007), Connections: An Introduction to the Economics of Networks, Princeton: Princeton University Press.

[50] Granovetter, M.S. (1973), "The strength of weak ties," American Journal of Sociology $78,1360-1380$.

[51] Granovetter, M.S. (1974), Getting a Job: A Study of Contacts and Careers, Cambridge, MA: Harvard University Press.

[52] Granovetter, M.S. (1979), "Placement as brokerage: Information problems in the labor market for rehabilitated workers," In: D. Vandergoot and J.D. Worrall (Eds.), Placement in Rehabilitation: A Career Development Perspective, Baltimore, MD: University Park Press, pp. 83-101.

[53] Granovetter, M.S. (1983), "The strength of weak ties: A network theory revisited," Sociological Theory 1, 201-233.

[54] Green, P.G., L.M. Tigges and I. Browne (1995), "Social resources, job search, and poverty in Atlanta", Research in Community Sociology 5, 161-182.

[55] Green, P.Gary, L.M. Tigges and D. Diaz (1999), "Racial and ethnic differences in jobsearch strategies in Atlanta, Boston and Los Angeles," Social Science Quarterly 80, 263-278.

[56] Guest, A.M. and B.A. Lee (1983), "The social organization of local areas", Urban Affairs Quarterly 19, 217-240.

[57] Helsey, R.W. and W.C. Strange (2007), "Urban interactions and spatial structure," Journal of Economic Geography 7, 119-138.

[58] Henning C. and M. Lieberg (1996), "Strong ties or weak ties? Neighbourhood networks in a new perspective," Scandinavian Housing and Planning Research 13, 3-26. 
[59] Holland, C., Clark, A., Katz, J., and S. Peace (2007), "Social interactions in urban public space," Joseph Rowntree Foundation.

[60] Holzer, H.J. (1987), "Informal job search and black youth unemployment," American Economic Review 77, 446-452.

[61] Holzer, H. (1988), "Search method use by unemployed youth," Journal of Labor Economics $6,1-20$.

[62] Ihlanfeldt, K.R. (2006), "A primer on spatial mismatch within urban labor markets," In: R. Arnott and D. McMillen (Eds.), A Companion to Urban Economics, Boston: Blackwell Publishing, pp. 404-417.

[63] Ihlanfeldt, K. R. and D. Sjoquist (1998), "The spatial mismatch hypothesis: A review of recent studies and their implications for welfare reform," Housing Policy Debate 9, 849-892.

[64] Ioannides, Y.M. and D.L. Loury (2004), "Job information networks, neighborhood effects, and inequality," Journal of Economic Literature 42, 1056-1093.

[65] Ioannides, Y.M. and G. Topa (2010), "Neighborhood effects: Accomplishments and looking beyond them," Journal of Regional Science 50, 343-362.

[66] Ioannides, Y.M. (2011), From Neighborhoods to Nations: The Economics of Social Interactions, forthcoming.

[67] Jackson, M.O. (2008), Social and Economic Networks, Princeton: Princeton University Press.

[68] Kadushin, C. and D.J. Jones (1992), "Social networks and urban neighborhoods in New York city", City and Society 6, 58-75.

[69] Kain, J. (1968), "Housing segregation, negro employment, and metropolitan decentralization," Quarterly Journal of Economics 82, 175-197.

[70] Kan, K. (2007), "Residential mobility and social capital," Journal of Urban Economics 61, 436-457.

[71] Kasinitz, P. and J. Rosenberg (1996), "Missing the connection: Social isolation and employment on the Brooklyn waterfront," Social Problems 43, 180-93. 
[72] Katz, L.F., Kling, J.R. and J.B. Liebman (2001), "Moving to opportunity in Boston: Early results of a randomized mobility experiment," Quarterly Journal of Economics $116,607-654$.

[73] Kling, J.R., Ludwig, J. and L.F. Katz (2005), "Neighborhood effects on crime for female and male youth: Evidence from a randomized housing voucher experiment," Quarterly Journal of Economics 120, 87-130.

[74] Lai, G., N. Lin and S.-Y. Leung (1998), "Network resources, contact resources, and status attainment," Social Networks 20, 159-178.

[75] Laufer, J.K. and S. Winship (2004), "Perception vs. reality: Employer attitudes and the rebranding of workforce intermediaries," In: R.P. Giloth (Ed.), Workforce Intermediaries for the Twenty-First Century, Philadelphia: Temple University Press, pp. 216-240.

[76] Lin, N., W.M. Ensel and J.C. Vaughn (1981), "Social resources and strength of ties: Structural factors in occupational status attainment," American Sociological Review 46, 393-405.

[77] Marsden, P.V. and J.S. Hurlbert (1988), "Social resources and mobility outcomes: A replication and extension," Social Forces 66, 1038-1059.

[78] Mauer, D.C. and S.H. Ott (1999), "On the optimal structure of government subsidies for entreprise zones and other locational development programs," Journal of Urban Economics 45, 421-450.

[79] Mencken, F. C. and I. Winfield (1998), "In search of the "right stuff": The advantages and disadvantages of informal and formal recruiting practices in external labor markets," American Journal of Economics and Sociology 57, 135-153.

[80] Montgomery, J.D. (1991), "Social networks and labor-market outcomes: Toward an economic analysis," American Economic Review 81, 1408-1418.

[81] Montgomery, J.D. (1994), "Weak ties, employment, and inequality: An equilibrium analysis," American Journal of Sociology 99, 1212-1236.

[82] Mortensen, D. and T. Vishwanath (1994), "Personal contacts and earnings: It is who you know!," Labour Economics 1, 187-201. 
[83] Nagin, D.S., J.B. Rebitzer, S. Sanders and L.J. Taylor (2002), "Monitoring, motivation, and management: The determinants of opportunistic behavior in a field experiment," American Economic Review 92, 850-873.

[84] Newman, K.S. (1995), "Dead-end jobs," Brookings Review Fall, 24-27.

[85] Newman, K.S. (1999), No Shame in My Game, New York: Knopf.

[86] Otani, S. (1999), "Personal community networks in contemporary Japan", In: B. Wellman (Eds.), Networks in the Global Village: Life in Contemporary Communities, Boulder, CO: Westview Press, pp. 279-297.

[87] Papke, L. (1994), "Tax policy and urban development: evidence from the Indiana enterprise zone program," Journal of Public Economics 54, 37-49.

[88] Patacchini, E. and Y. Zenou (2008), "The strength of weak ties in crime," European Economic Review 52, 209-236.

[89] Pellizzari, M. (2010), "Do friends and relatives really help in getting a good job?" Industrial and Labor Relations Review 63, 494-510.

[90] Putnam R. (2007), "E Pluribus Unum: Diversity and community in the twenty first century; The 2006 Johan Skytte Prize Lecture," Scandinavian Political Studies, 30, $137-174$.

[91] Raphael, S. and Stoll, M.A. (2002), "Modest progress: The narrowing spatial mismatch between blacks and jobs in the 1990s," Washington, DC: The Brookings Institution.

[92] Rebitzer, J.B. (1995), "Is there a trade-off between supervision and wages? An empirical test of efficiency wage theory," Journal of Economic Behavior and Organization $28,107-129$.

[93] Rosenbaum, E. and L.E. Harris (2001), "Residential mobility and opportunities: Early impacts of the Moving to Opportunity demonstration program in Chicago," Housing Policy Debate 12, 321-346.

[94] Rosenthal, S.S. (1988), "A residence time model of housing markets," Journal of Public Economics 36, 87-109.

[95] Ruppert, P. and E. Wasmer (2009), "Housing and the labor market: Time to move and aggregate unemployment," IZA Discussion Paper No. 4172. 
[96] Saloner, G. (1985), "Old boy networks as screening nechanism," Journal of Labor Economics 3, 255-267.

[97] Selod, H. and Y. Zenou (2006), "City-structure, job search, and labour discrimination. Theory and policy implications," Economic Journal 116, 1057-1087.

[98] Sigelman, L., Bledsoe, T., Welch, S., and M.W. Combs (1996), "Making contact? Black-white social interaction in an urban setting," American Journal of Sociology 101, 1306-1332.

[99] Shapiro, C., Stiglitz, J.E. (1984), "Equilibrium unemployment as a worker discipline device," American Economic Review 74, 433-444.

[100] Strobl, E. and F. Walsh (2007), "Estimating the shirking model with variable effort," Labour Economics 14, 623-637.

[101] Topa, G. (2001), "Social interactions, local spillovers and unemployment," Review of Economic Studies 68, 261-295.

[102] Topa, G. (2011), "Labor markets and referrals," In: J. Benhabib, A. Bisin and M.O. Jackson (Eds.), Handbook of Social Economics, Amsterdam: Elsevier Science, forthcoming.

[103] Van Ours, J.C. (1994), "Matching unemployed and vacancies at the public employment office," Empirical Economics 19, 37-54.

[104] Vega-Redondo, F. (2007), Complex Social Networks, Econometric Society Monograph Series, Cambridge: Cambridge University Press.

[105] Wahba, J. and Y. Zenou (2005), "Density, social networks and job search methods: Theory and application to Egypt," Journal of Development Economics 78, 443-473.

[106] Wasmer, E. and Y. Zenou (2002), "Does city structure affect job search and welfare?," Journal of Urban Economics 51, 515-541.

[107] Weinberg, B.A., P.B. Reagan and J.J. Yankow. (2004), "Do neighborhoods affect hours worked: Evidence from longitudinal data," Journal of Labor Economics 22, 891-924.

[108] Wellman, B. (1996), "Are personal communities local? A dumptarian reconsideration," Social Networks 18, 347-354. 
[109] Wial, H. (1991), "Getting a good job: Mobility in a segmented labor market," Industrial Relations 30, 396-416.

[110] Wilson, W.J. (1996), When Work Disappears: The World of the New Urban Poor, New York: Knopf.

[111] Yakubovich, V. (2005), "Weak ties, information, and influence: How workers find jobs in a local Russian labor market," American Sociological Review 70, 3, 408-421.

[112] Yinger, J. (1986), "Measuring racial discrimination with fair housing audits," American Economic Review 76, 881-93.

[113] Yinger, J. (1997), "Cash in your face: The cost of racial and ethnic discrimination in housing," Journal of Urban Economics 42, 339-65.

[114] Zenou, Y. (2006a), "Efficiency wages and unemployment in cities: The case of high relocation costs," Regional Science and Urban Economics 36, 49-71.

[115] Zenou, Y. (2006b), "Urban labor economic theory,", In: R. Arnott and D. McMillen (Eds.), A Companion to Urban Economics, Boston: Blackwell Publishing, pp. 418-439.

[116] Zenou, Y. (2008), "The spatial mismatch hypothesis," In: L. Blume and S. Durlauf (Eds.), The New Palgrave, A Dictionary of Economics, Second Edition, London: MacMillan Press.

[117] Zenou, Y. (2009), Urban Labor Economics, Cambridge: Cambridge University Press. 


\section{Appendix}

Proof of Proposition 1: We establish the proof in two steps. First, Lemma 1 characterizes all steady-state dyad flows. Lemma 2 then provides conditions for their existence.

Lemma 1 There exists at most two different steady-state equilibria: (i) a full-unemployment equilibrium $\mathcal{U}$ such that $e^{*}=0$ and $u^{*}=1,\left(\right.$ ii) an interior equilibrium $\mathcal{I}$ such that $0<e^{*}<1$ and $0<u^{*}<1$.

Proof. By combining (5) to (8), we easily obtain:

$$
e^{*}=\left[\left(1-\omega+\omega e^{*}\right) \lambda+\delta\right] \frac{2 \omega e^{*} \lambda}{\delta^{2}} d_{0}^{*}
$$

We consider two different cases.

( $i$ ) If $e^{*}=0$, then equation (50) is satisfied. Furthermore, using (5) and (6), this implies that $d_{1}^{*}=d_{2}^{*}=0$ and, using (7) and (9), we have $d_{0}^{*}=1 / 2$ and $u^{*}=1$. This is referred to as steady-state $\mathcal{U}$ (full unemployment).

(ii) If $e^{*}>0$, then solving equation (50) yields:

$$
e^{*}=\frac{1}{\lambda \omega}\left[\frac{\delta^{2}}{2 \omega \lambda d_{0}^{*}}-\delta\right]-\frac{(1-\omega)}{\omega}
$$

Define $Z=(1-\omega) / \omega, B=\delta /(\lambda \omega)$. This equation can now be written as:

$$
e^{*}=\frac{B^{2}}{2 d_{0}^{*}}-B-Z
$$

Moreover, by combining (5) and (6), we obtain:

$$
d_{1}^{*}=\frac{2 e^{*}}{B} d_{0}^{*}, \quad d_{2}^{*}=\frac{\left(Z+e^{*}\right) e^{*}}{B^{2}} d_{0}^{*}
$$

- Let us first focus on the case where $e^{*}=1$. In that case, it has to be that only $d_{2}$-dyads exist and thus $d_{0}^{*}=d_{1}^{*}=0$, which, using (52) implies that: $d_{2}^{*}=0$. So this case is not possible.

- Let us now thus focus on the case: $0<e^{*}<1$ (which implies that $0<u^{*}<1$ )

By plugging (51) and (52) in (7) and after some algebra, we obtain that $d_{0}^{*}$ solves $\Phi\left(d_{0}^{*}\right)=$ 0 where $\Phi(x)$ is the following second-order polynomial:

$$
\Phi\left(d_{0}^{*}\right)=-\frac{Z}{B} x^{2}-\frac{(1+Z)}{2} x+\left(\frac{B}{2}\right)^{2}
$$




\section{Lemma 2}

(i) The steady-state equilibrium $\mathcal{U}$ always exists.

(iv) The steady-state equilibrium $\mathcal{I}$ exists when $\delta<\lambda[\omega+\sqrt{\omega(4-3 \omega)}] / 2$.

\section{Proof.}

(i) In this equilibrium $e^{*}=0$, which implies that $h(e)=(1-\omega) \lambda$ and $q(e)=0$. There are only $d_{0}$-dyads so all workers are unemployed and will never receive a job offer since $q(e)=0$. So when a $d_{0}$-dyad is formed it is never destroyed and thus this equilibrium is always sustainable.

(ii) We know from Lemma 1 that a steady-state $\mathcal{I}$ exists and that $e^{*} \neq 1$. We now have to check that $e^{*}>0$ and $0<d_{0}^{*}<1 / 2$. Let us thus verify whether there exists some $0<d_{0}^{*}<1 / 2$ such that $\Phi\left(d_{0}^{*}\right)=0$, where $\Phi(\cdot)$ is given by $(53)$. We have $\Phi(0)=(B / 2)^{2}>0$ and $\Phi^{\prime}(0)=-(1+Z) / 2<0$. Therefore, (53) has a unique positive root smaller than $1 / 2$ if and only if

$$
\Phi(1 / 2)=\frac{1}{4}\left[B^{2}-(1+Z)-\frac{Z}{B}\right]=\frac{1}{4}\left(1+\frac{1}{B}\right)\left(B^{2}-B-Z\right)<0 .
$$

The unique positive solution to $x^{2}-x-Z=0$ is $[1+\sqrt{(4-3 \omega) / \omega}] / 2$. Then, $d_{0}^{*}<1 / 2$ if and only if $B<[1+\sqrt{(4-3 \omega) / \omega}] / 2$, equivalent to:

$$
\frac{\delta}{\lambda}<\frac{\omega+\sqrt{\omega(4-3 \omega)}}{2}
$$

Observe that $d_{0}^{*}<1 / 2$ guarantees that $e^{*}>0$.

\section{Proof of Proposition 4:}

(i) By totally differentiating (12), we obtain:

$$
\frac{\partial d_{0}^{*}}{\partial \omega}=\frac{\frac{\lambda}{\delta} d_{0}^{2}+\frac{1}{2 \omega^{2}} d_{0}-\frac{\delta^{2}}{2 \lambda^{2} \omega^{3}}}{2 \frac{\lambda(1-\omega)}{\delta} d_{0}+\frac{1}{2 \omega}}
$$

and thus

$$
\operatorname{sgn} \frac{\partial d_{0}^{*}}{\partial \omega}=\operatorname{sgn}\left[\frac{\lambda}{\delta} d_{0}^{2}+\frac{1}{2 \omega^{2}} d_{0}-\frac{\delta^{2}}{2 \lambda^{2} \omega^{3}}\right]
$$

Let us study

$$
\Phi\left(d_{0}\right) \equiv \frac{\lambda}{\delta} d_{0}^{2}+\frac{1}{2 \omega^{2}} d_{0}-\frac{\delta^{2}}{2 \lambda^{2} \omega^{3}}
$$




$$
\begin{gathered}
\Phi(0)=-\frac{\delta^{2}}{2 \lambda^{2} \omega^{3}}<0 \\
\Phi^{\prime}\left(d_{0}\right)=2 \frac{\lambda}{\delta} d_{0}+\frac{1}{2 \omega^{2}}>0 \text { when } d_{0} \geq 0 \\
\Phi^{\prime \prime}\left(d_{0}\right)=2 \frac{\lambda}{\delta}>0
\end{gathered}
$$

We have a quadratic function that crosses only once the positive orthant. Let us calculate $\widehat{d_{0}}>0$ the value for which $\Phi\left(d_{0}\right)$ crosses the $d_{0}$-axis. For that, we have to solve: $\Phi\left(\widehat{d_{0}}\right)=0$. It is easy to verify that:

$$
\widehat{d}_{0}=\frac{\delta}{4 \lambda \omega^{2}}\left(\sqrt{1+\frac{8 \delta \omega}{\lambda}}-1\right)>0
$$

It should be clear that if $\widehat{d}_{0}<1 / 2$, then $\Phi\left(d_{0}\right)<0$ for $0<d_{0}<1 / 2$ and thus $\frac{\partial d_{0}^{*}}{\partial \omega}<0$. Let us thus check that $\widehat{d}_{0}<1 / 2$, which is equivalent to:

$$
\Omega\left(\frac{\delta}{\lambda}\right) \equiv 2\left(\frac{\delta}{\lambda}\right)^{3}-\omega \frac{\delta}{\lambda}-\omega^{3}<0
$$

We have:

$$
\begin{aligned}
\Omega(0) & =-\omega^{3}<0 \\
\Omega^{\prime}\left(\frac{\delta}{\lambda}\right) & =6\left(\frac{\delta}{\lambda}\right)^{2}-\omega
\end{aligned}
$$

with

$$
\Omega^{\prime}\left(\frac{\delta}{\lambda}\right)<0 \Leftrightarrow \frac{\delta}{\lambda}<\sqrt{\frac{\omega}{6}}
$$

As a result, when $\frac{\delta}{\lambda}<\sqrt{\frac{\omega}{6}}, \widehat{d_{0}}<1 / 2$ and thus $\frac{\partial d_{0}^{*}}{\partial \omega}<0$. Since we are in equilibrium $\mathcal{I}$, condition (10) has to hold, i.e.

$$
\frac{\delta}{\lambda}<\frac{\omega+\sqrt{\omega(4-3 \omega)}}{2}
$$

Let us show that

$$
\sqrt{\frac{\omega}{6}}<\frac{\omega+\sqrt{\omega(4-3 \omega)}}{2}
$$

This inequality is equivalent to:

$$
4+2 \sqrt{\omega(4-3 \omega)}>\frac{2}{3}+2 \omega
$$

which is always true since $\omega<1$ and thus $4>\frac{2}{3}+2 \omega$. Consequently, when condition (22) holds, i.e. $\frac{\delta}{\lambda}<\sqrt{\frac{\omega}{6}}, \frac{\partial d_{0}^{*}}{\partial \omega}<0$, then condition (10) is always satisfied. 
(ii) By totally differentiating (11), we obtain:

$$
\begin{aligned}
\frac{\partial e^{*}}{\partial \omega} & =\frac{\partial B}{\partial \omega}\left(\frac{B}{2}-1\right)-\frac{B^{2}}{4} \frac{1}{d_{0}} \frac{\partial d_{0}^{*}}{\partial \omega}-\frac{\partial Z}{\partial \omega} \\
& =\frac{-\delta}{\lambda \omega^{2}}\left(\frac{\delta}{2 \lambda \omega}-1\right)-\frac{\delta^{2}}{4 \lambda^{2} \omega^{2}} \frac{1}{d_{0}} \frac{\partial d_{0}^{*}}{\partial \omega}+\frac{1}{\omega^{2}} \\
& =\frac{\delta}{\lambda \omega^{2}}-\frac{\delta^{2}}{4 \lambda^{2} \omega^{2}} \frac{1}{d_{0}} \frac{\partial d_{0}^{*}}{\partial \omega}+\frac{1}{\omega^{2}}-\frac{\delta^{2}}{2 \lambda^{2} \omega^{3}} \\
& =\frac{1}{\omega^{2}}\left[\frac{\delta}{\lambda}-\frac{\delta^{2}}{4 \lambda^{2}} \frac{1}{d_{0}} \frac{\partial d_{0}^{*}}{\partial \omega}+1-\frac{\delta^{2}}{2 \lambda^{2} \omega}\right]
\end{aligned}
$$

Thus, we have:

$$
\frac{\partial e^{*}}{\partial \omega}>0 \Leftrightarrow \frac{\delta}{\lambda}-\frac{\delta^{2}}{4 \lambda^{2}} \frac{1}{d_{0}} \frac{\partial d_{0}^{*}}{\partial \omega}+1>\frac{\delta^{2}}{2 \lambda^{2} \omega}
$$

Since $\frac{\partial d_{0}^{*}}{\partial \omega}<0$ when $(22)$ holds, then it suffices to show that:

$$
\frac{\delta}{\lambda}+1>\frac{\delta^{2}}{2 \lambda^{2} \omega}
$$

which is always true if

$$
\frac{\delta^{2}}{2 \lambda^{2} \omega}<1
$$

This is equivalent to:

$$
\frac{\delta}{\lambda}<\sqrt{2 \omega}
$$

But since

$$
\sqrt{\frac{\omega}{6}}<\sqrt{2 \omega}
$$

is always true, then condition (22) guarantees that both

$$
\frac{\partial d_{0}^{*}}{\partial \omega}<0 \text { and } \frac{\partial e^{*}}{\partial \omega}>0
$$

Since $e^{*}=1-u^{*}, \frac{\partial e^{*}}{\partial \omega}>0 \Leftrightarrow \frac{\partial u^{*}}{\partial \omega}<0$. To summarize, when condition (22) holds, i.e. $\frac{\delta}{\lambda}<\sqrt{\frac{\omega}{6}}$, we have: $\frac{\partial d_{0}^{*}}{\partial \omega}<0, \frac{\partial e^{*}}{\partial \omega}>0, \frac{\partial u^{*}}{\partial \omega}<0$, and condition (10) is always satisfied.

Finally, from (13) and (14), it is easy to see that $\frac{\partial d_{1}^{*}}{\partial \omega}$ and $\frac{\partial d_{2}^{*}}{\partial \omega}$ cannot be signed. 


\section{Proof of Proposition 10:}

Lemma 3 There exist two types of steady-state equilibria: (i) a full-unemployment equilibrium $\mathcal{U}$ such that $e_{j}^{*}=0$ and $u_{j}^{*}=1$, (ii) an interior equilibrium $\mathcal{I}$ such that $0<e_{j}^{*}<1$ and $0<u_{j}^{*}<1, \forall j=B, W$.

Proof. By combining (42) to (46), we easily obtain:

$$
\begin{gathered}
e_{j}^{*}=\frac{\left[\left(1-\bar{\omega}_{j}\right) \lambda+\bar{\omega}_{j} \lambda\left(\frac{N_{B} e_{B}^{*}+N_{W} e_{W}^{*}}{N}\right)+\delta\right] 2 \bar{\omega}_{j} \lambda\left(\frac{N_{B} e_{B}^{*}+N_{W} e_{W}^{*}}{N}\right)}{\delta^{2} N_{j}} d_{0 j}^{*} \\
e_{j}^{*}=\frac{\left[\left(1-\bar{\omega}_{j}\right) \lambda N+\bar{\omega}_{j} \lambda\left(N_{B} e_{B}^{*}+N_{W} e_{W}^{*}\right)+\delta N\right] 2 \bar{\omega}_{j} \lambda\left(N_{B} e_{B}^{*}+N_{W} e_{W}^{*}\right)}{\delta^{2} N^{2} N_{j}} d_{0 j}^{*}
\end{gathered}
$$

We consider the following different cases.

(ia) If $e_{B}^{*}=e_{W}^{*}=0$, then equation (54) is satisfied. We have that $d_{1 j}^{*}=d_{2 j}^{*}=0$ and $d_{0}^{*}=N_{j} / 2$ and $u_{j}^{*}=1$. This is referred to as steady-state $\mathcal{U}$ (full unemployment).

(ib) If $e_{B}^{*}=0$ and $e_{W}^{*}>0$, then solving equation (50) yields for blacks:

$$
0=\frac{\left[\left(1-\bar{\omega}_{j}\right) \lambda N+\bar{\omega}_{j} \lambda N_{W} e_{W}^{*}+\delta N\right] 2 \bar{\omega}_{j} \lambda N_{W} e_{W}^{*}}{\delta^{2} N^{2} N_{j}} d_{0 j}^{*}
$$

The only way this equation can hold is that $e_{W}^{*}=0$ (indeed $d_{0 B}^{*}$ cannot be equal to zero since this implies that $d_{2 B}^{*}=d_{1 B}^{*}=0$ and thus $d_{0 B}^{*}=\frac{N_{W}}{2}-d_{2 B}^{*}-d_{1 B}^{*}$ cannot hold) and we are back in case $(i a)$ where $e_{B}^{*}=e_{W}^{*}=0$ and steady-state $\mathcal{U}$ prevails.

(ic) If $e_{W}^{*}=0$ and $e_{B}^{*}>0$, then by a similar reasoning as in case $(i b)$, we end up with $e_{B}^{*}=e_{W}^{*}=0$ and steady-state $\mathcal{U}$ prevails.

(ii) Let us assume that $e_{B}^{*}>0$ and $e_{W}^{*}>0$. Let us see if it is possible to have either $e_{B}^{*}=1$ or $e_{W}^{*}=1$ or both. If either $e_{B}^{*}=1$ or $e_{W}^{*}=1$ or both $e_{B}^{*}=e_{W}^{*}=1$, then it is easily verified that $d_{0 j}^{*}=d_{1 j}^{*} / 2-d_{1 j}^{*}=-d_{1 j}^{*} / 2<0$, which is impossible. As a result, if $e_{B}^{*}>0$ and $e_{W}^{*}>0$, then it has to be that $e_{B}^{*}<1$ and $e_{W}^{*}<1$. We call this steady-state equilibrium $\mathcal{I}$ because it is an interior equilibrium for which $0<e_{B}^{*}<1$ and $0<e_{W}^{*}<1$.

Let us now focus on the case $0<e_{B}^{*}<1$ and $0<e_{W}^{*}<1$ (which implies that $0<u_{B}^{*}<1$ and $0<u_{W}^{*}<1$ ) and prove Proposition 10. Using (42) to (46), we have:

$$
\begin{gathered}
d_{2 j}^{*}=\frac{\lambda^{2} \bar{\omega}_{j}\left[1-\bar{\omega}_{j}+\bar{\omega}_{j}\left(\frac{N_{B}}{N} e_{B}^{*}+\frac{N_{W}}{N} e_{W}^{*}\right)\right]\left(\frac{N_{B}}{N} e_{B}^{*}+\frac{N_{W}}{N} e_{W}^{*}\right)}{\delta^{2}} d_{0 j}^{*} \\
d_{1 j}^{*}=\frac{2 \bar{\omega}_{j} \lambda\left(\frac{N_{B}}{N} e_{B}^{*}+\frac{N_{W}}{N} e_{W}^{*}\right)}{\delta} d_{0 j}^{*}
\end{gathered}
$$




$$
\begin{gathered}
d_{0 j}^{*}=\frac{N_{j}}{2}-d_{2 j}^{*}-d_{1 j}^{*} \\
N_{j} e_{j}^{*}=2 d_{2 j}^{*}+d_{1 j}^{*}
\end{gathered}
$$

Observe that:

$$
N_{B} e_{B}^{*}=2 d_{2 B}^{*}+d_{1 B}^{*} \text { and } N_{W} e_{W}^{*}=2 d_{2 W}^{*}+d_{1 W}^{*}
$$

Thus

$$
N_{B} e_{B}^{*}+N_{W} e_{W}^{*}=2 d_{2 B}^{*}+d_{1 B}^{*}+2 d_{2 W}^{*}+d_{1 W}^{*}
$$

This is equivalent to:

$$
\begin{aligned}
N_{B} e_{B}^{*}+N_{W} e_{W}^{*}= & \frac{2 \lambda \bar{\omega}_{B} d_{0 B}^{*}\left(\frac{N_{B}}{N} e_{B}^{*}+\frac{N_{W}}{N} e_{W}^{*}\right)\left[\lambda\left(1-\bar{\omega}_{B}\right)+\left(\frac{N_{B}}{N} e_{B}^{*}+\frac{N_{W}}{N} e_{W}^{*}\right)\left(\lambda \bar{\omega}_{B}+\delta\right)\right]}{\delta^{2}} \\
& +\frac{2 \lambda \bar{\omega}_{W} d_{0 W}^{*}\left(\frac{N_{B}}{N} e_{B}^{*}+\frac{N_{W}}{N} e_{W}^{*}\right)\left[\lambda\left(1-\bar{\omega}_{W}\right)+\left(\frac{N_{B}}{N} e_{B}^{*}+\frac{N_{W}}{N} e_{W}^{*}\right)\left(\lambda \bar{\omega}_{W}+\delta\right)\right]}{\delta^{2}}
\end{aligned}
$$

which is equivalent to:

$$
\begin{aligned}
N^{2} \delta^{2}= & 2 \lambda \bar{\omega}_{B} d_{0 B}^{*}\left[\lambda\left(1-\bar{\omega}_{B}\right) N+\left(N_{B} e_{B}^{*}+N_{W} e_{W}^{*}\right)\left(\lambda \bar{\omega}_{B}+\delta\right)\right] \\
& +2 \lambda \bar{\omega}_{W} d_{0 W}^{*}\left[\lambda\left(1-\bar{\omega}_{W}\right) N+\left(N_{B} e_{B}^{*}+N_{W} e_{W}^{*}\right)\left(\lambda \bar{\omega}_{W}+\delta\right)\right]
\end{aligned}
$$

This is equivalent to:

$$
\begin{aligned}
& 2 \lambda\left(N_{B} e_{B}^{*}+N_{W} e_{W}^{*}\right)\left[\bar{\omega}_{B} d_{0 B}^{*}\left(\lambda \bar{\omega}_{B}+\delta\right)+\bar{\omega}_{W} d_{0 W}^{*}\left(\lambda \bar{\omega}_{W}+\delta\right)\right] \\
= & N^{2} \delta^{2}-2 \lambda^{2} \bar{\omega}_{B} d_{0 B}^{*}\left(1-\bar{\omega}_{B}\right) N-2 \lambda^{2} \bar{\omega}_{W} d_{0 W}^{*}\left(1-\bar{\omega}_{W}\right) N
\end{aligned}
$$

which is equivalent to:

$$
\frac{N_{B} e_{B}^{*}+N_{W} e_{W}^{*}}{N}=\frac{N \delta^{2}-2 \lambda^{2} \bar{\omega}_{B} d_{0 B}^{*}\left(1-\bar{\omega}_{B}\right)-2 \lambda^{2} \bar{\omega}_{W} d_{0 W}^{*}\left(1-\bar{\omega}_{W}\right)}{2 \lambda\left[\bar{\omega}_{B} d_{0 B}^{*}\left(\lambda \bar{\omega}_{B}+\delta\right)+\bar{\omega}_{W} d_{0 W}^{*}\left(\lambda \bar{\omega}_{W}+\delta\right)\right]}
$$

which is (47). In other words, $e_{B}^{*}+e_{W}^{*}$ only depends on $d_{0 B}^{*}$ and $d_{0 W}^{*}$ and exogenous variables.

- Let us now show that $e_{B}^{*}<e_{W}^{*}$. Using (54), we have:

$$
\begin{aligned}
e_{B}^{*} & =\frac{\left[\bar{\omega}_{B} \lambda\left(\frac{N_{B} e_{B}^{*}+N_{W} e_{W}^{*}}{N}-1\right)+\lambda+\delta\right] 2 \bar{\omega}_{B} \lambda\left(\frac{N_{B} e_{B}^{*}+N_{W} e_{W}^{*}}{N}\right)}{\delta^{2} N_{B}} d_{0 B}^{*} \\
e_{W}^{*} & =\frac{\left[\bar{\omega}_{W} \lambda\left(\frac{N_{B} e_{B}^{*}+N_{W} e_{W}^{*}}{N}-1\right)+\lambda+\delta\right] 2 \bar{\omega}_{W} \lambda\left(\frac{N_{B} e_{B}^{*}+N_{W} e_{W}^{*}}{N}\right)}{\delta^{2} N_{W}} d_{0 W}^{*}
\end{aligned}
$$


As a result, $e_{B}^{*}<e_{W}^{*}$ is equivalent to:

$$
\begin{gathered}
\frac{\left[\bar{\omega}_{B} \lambda\left(\frac{N_{B} e_{B}^{*}+N_{W} e_{W}^{*}}{N}-1\right)+\lambda+\delta\right] 2 \bar{\omega}_{B} \lambda\left(\frac{N_{B} e_{B}^{*}+N_{W} e_{W}^{*}}{N}\right)}{\delta^{2} N_{B}} d_{0 B}^{*} \\
<\frac{\left[\bar{\omega}_{W} \lambda\left(\frac{N_{B} e_{B}^{*}+N_{W} e_{W}^{*}}{N}-1\right)+\lambda+\delta\right] 2 \bar{\omega}_{W} \lambda\left(\frac{N_{B} e_{B}^{*}+N_{W} e_{W}^{*}}{N}\right)}{\delta^{2} N_{W}} d_{0 W}^{*} \\
\Leftrightarrow \frac{\lambda \bar{\omega}_{B}\left(\frac{N_{B} e_{B}^{*}+N_{W} e_{W}^{*}}{N}-1\right)+\lambda+\delta}{\lambda \bar{\omega}_{W}\left(\frac{N_{B} e_{B}^{*}+N_{W} e_{W}^{*}}{N}-1\right)+\lambda+\delta}<\frac{\bar{\omega}_{W}\left(\frac{N_{B} e_{B}^{*}+N_{W} e_{W}^{*}}{N}\right) N_{B} d_{0 W}^{*}}{\bar{\omega}_{B}\left(\frac{N_{B} e_{B}^{*}+N_{W} e_{W}^{*}}{N}\right) N_{W} d_{0 B}^{*}} \\
\Leftrightarrow \frac{\lambda \bar{\omega}_{B}\left(\frac{N_{B} e_{B}^{*}+N_{W} e_{W}^{*}}{N}-1\right)+\lambda+\delta}{\lambda \bar{\omega}_{W}\left(\frac{N_{B} e_{B}^{*}+N_{W} e_{W}^{*}}{N}-1\right)+\lambda+\delta}<\frac{N_{B} \bar{\omega}_{W} d_{0 W}^{*}}{N_{W} \bar{\omega}_{B} d_{0 B}^{*}}
\end{gathered}
$$

Since, by Proposition $9, \bar{\omega}_{B}<\bar{\omega}_{W}$, then

$$
\frac{\lambda \bar{\omega}_{B}\left(e_{B}^{*}+e_{W}^{*}-1\right)+\lambda+\delta}{\lambda \bar{\omega}_{W}\left(e_{B}^{*}+e_{W}^{*}-1\right)+\lambda+\delta}<1
$$

Thus a sufficient condition for $e_{B}^{*}<e_{W}^{*}$ is

$$
\frac{N_{B} \bar{\omega}_{W} d_{0 W}^{*}}{N_{W} \bar{\omega}_{B} d_{0 B}^{*}}>1
$$

that is:

$$
\Leftrightarrow \frac{\bar{\omega}_{W}}{\bar{\omega}_{B}}>\frac{N_{W}}{N_{B}} \frac{d_{0 B}^{*}}{d_{0 W}^{*}}
$$

If the ratio $\bar{\omega}_{W} / \bar{\omega}_{B}$ is large enough, then this inequality is true. 